\title{
Dynamical downscaling simulation and projection for mean and extreme temperature and precipitation over central Asia
}

\author{
Xian Zhu ${ }^{1,2} \cdot$ Zhigang Wei $^{3} \cdot$ Wenjie Dong ${ }^{1,2}$. Zhenming $\mathrm{Ji}^{1,2} \cdot$ Xiaohang Wen $^{4} \cdot$ Zhiyuan Zheng $^{1,2}$. Dongdong Yan ${ }^{3}$. \\ Deliang Chen ${ }^{5}$
}

Received: 25 July 2019 / Accepted: 4 February 2020 / Published online: 24 February 2020

(c) The Author(s) 2020

\begin{abstract}
As a typical arid and semi-arid area, central Asia (CA) has scarce water resources and fragile ecosystems that are particularly sensitive and vulnerable to climate change. In this study, dynamic downscaling was conducted to produce a regional dataset that incorporated the time period 1986-2100 for the CA. The results show that dynamic downscaling significantly improves the simulation for the mean and extreme climate over the CA, compared to the driving CCSM4 model. We show that significant warming will occur over CA with $2.0^{\circ} \mathrm{C}$ and $5.0^{\circ} \mathrm{C}$ increasing under the RCP4.5 and RCP8.5 scenarios, respectively by the end of twenty-first century. The daily maximum temperature, the daily minimum temperature and the annual total number of days with a minimum temperature greater than $25^{\circ} \mathrm{C}$ will also increase significantly. The annual total number of days with a minimum temperature less than $0{ }^{\circ} \mathrm{C}$ will decrease significantly. Long-term trends in the projected winter precipitation under different emission scenarios exhibit robust and increasing changes during the twenty-first century, especially under the RCP8.5 scenario with an increasing about $0.1 \mathrm{~mm} /$ day. Significant differences are shown in the projection of precipitationrelated indices over CA under different emission scenarios, and the impact of emissions is apparent for the number of days with $\geq 10 \mathrm{~mm}$ of precipitation, the density of precipitation on days with $\geq 1 \mathrm{~mm}$ of precipitation, and particularly for the maximum consecutive number of dry days that will increase significantly under the RCP8.5 scenario. Therefore, reduced greenhouse gases emissions have implications for mitigating extreme drought events over the CA in the future.
\end{abstract}

Keywords Central Asia $\cdot$ Dynamic downscaling $\cdot$ Extreme $\cdot$ Projection

\section{Introduction}

Wenjie Dong

dongwj3@mail.sysu.edu.cn

$\triangle$ Zhenming Ji

jizhm3@mail.sysu.edu.cn

1 School of Atmospheric Sciences, Sun Yat-Sen University, Zhuhai 519082, China

2 Southern Marine Science and Engineering Guangdong Laboratory, Zhuhai 519082, China

3 State Key Laboratory of Earth Surface Processes and Resource Ecology, Faculty of Geographical Science, Beijing Normal University, Beijing 100875, China

4 Plateau Atmosphere and Environment Key Laboratory of Sichuan Province, School of Atmospheric Sciences, Chengdu University of Information Technology, Chengdu 610225, China

5 Regional Climate Group, Department of Earth Sciences, University of Gothenburg, 46040530 Gothenburg, Sweden
Central Asia (CA) is located within continental Eurasia and a long distance from the sea. It is a typical arid and semiarid region and is very sensitive and vulnerable to variations in climate ( $\mathrm{Li}$ et al. 2015; Zhang et al. 2016). Under the background of global warming, extreme events such as heat waves, and droughts are occurring more frequently in this region than in humid regions, which results in a greater threat to the vulnerable ecosystems and human society of CA (Hu et al. 2014). The warming rate is currently larger than that during any other time in its recorded history (Chen et al. 2009; Davi et al. 2015), which is mainly caused by anthropogenic forcing, particularly the greenhouse gases (GHG) forcing (Peng et al. 2019), and the accelerating warming rate in the recent five decades is much higher than the global land average. At the end of the twenty-first century, the annual (ANN) mean temperature of CA will increase by as much as $7{ }^{\circ} \mathrm{C}$ (Mannig et al. 2013; Peng et al. 2019). A temperature 
rise of this scale will threaten the equilibrium of the local ecosystem (Pan et al. 2014; Zhang and Ren 2017; Wu et al. 2019). With global warming, the precipitation anomalies of the CA have increased the nonuniformity of water resources across the CA and led to increasingly severe aridification (Narisma et al. 2007; Chen et al. 2009). The hydrological system of the CA has also responded strongly to global warming and has become a major issue in CA-related climate change research (Giorgi 2006; Viviroli et al. 2011). Researches have shown that the amount of precipitation in the CA has increased over the past century (Chen et al. 2011; Huang et al. 2014; Hu et al. 2017). With the significant warming over CA during the past several decades, the temperature and precipitation extremes of the CA have experienced a dramatic change, especially for extreme temperatures which have increased significantly (Wang et al. 2017).

At present, global climate models (GCMs) are the most important tools for providing valuable information about climate change and estimating future climates under various scenarios of greenhouse gas emissions on global and subcontinental scales (IPCC 2013). The GCMs of the Coupled Model Inter-comparison Project's fifth phase (CMIP5) were significantly improved over those of the previous generation, CMIP3 (Taylor et al. 2012). However, the horizontal resolution of GCMs is relatively low (Meehl et al. 2007), which restricts their ability to capture the characteristics of regional climate. There are significant quantitative and qualitative errors of the simulation by GCMs for the climate factors such as temperature, precipitation, snow accumulation, and windspeed over the CA and the Tibetan Plateau (Wei and Dong 2015; You et al. 2016; Zhu et al. 2017; You et al. 2018). Therefore, using GCMs to project regional climate change will result in unreliable information, especially for the regions with complex topography such as the CA and the Tibetan Plateau. A dynamic downscaling method can be used to produce information about regional climate change characteristics at a higher resolution than GCMs, which has been widely used to simulate past and future finescale climates (Gao et al. 2006; Ji and Kang 2013, 2015; Niu et al. 2015; Shi et al. 2017; Xu et al. 2017; Zhu et al. 2019). Compared to GCMs, regional climate models (RCMs) were essentially developed with the aim of downscaling climate fields produced by coarse resolution GCMs, thereby providing information at fineer, sub-GCM grid scales which is more suitable for studies of regional applications in vulnerability, impacts and adaptation (VIA) assessments. They can better resolve detailed regional atmospheric and terrestrial processes. Generally, improved resolution leads to a better representation of finer-scale physical processes, as well as effects of details in topography, land-sea distribution, and land surface processes (Rasmussen et al. 2011; Xue et al. 2014; Filippo Giorgi 2019). Furthermore, methods for correcting biases in the outputs of GCMs have been developed, further improving the results obtained from dynamical downscaling (Bruyère et al. 2014; Xu and Yang 2015). The high-resolution RCM can better resolve fine-scale topography, land cover, and middle- and small-scale convective processes through dynamic downscaling and will improve the simulation significantly (Mannig et al. 2013; Qiu et al. 2017). However, different physical parameterizations used by RCM may have strong influences on the RCM simulations, which is considered to be a major source of error in RCMs (Hong and Kanamitsu 2014). For example, for regions with complex topography, the choice of land surface model parameterization (LSM) has been found to have the greatest impact on the accuracy of RCMs (Kala et al. 2015).

"The Belt and Road" includes the Silk Road Economic Belt and the twenty-first century Maritime Silk Road. The Belt and Road Initiative is a systematic project, which should be jointly built through consultation to meet the interests of all, and efforts should be made to integrate the development strategies of the countries along the Belt and Road. CA is located in the key area of "The Belt and Road" which is one of the largest arid and semiarid areas in the world and has a population of almost 60 million people. Because of climate conditions, CA is lack of freshwater. The inhomogeneous climates over CA, with great spatial variability, are largely due to heterogeneity associated with the complex terrain, including high mountain ranges and flat low-level plains (Narama et al. 2009). As such, the ecosystem and societal development in arid CA is highly vulnerable to climate change (Peng et al. 2019). In order to solve the problem of a limited availability of high resolution and quality climate data in the region, dynamical downscaling is necessary for climate projections over CA. Moreover, the high-resolution climate information obtained from dynamic downscaling could be applied to collaborative and crossover research, such as impacts on glacier change, water resources, and agricultural development that may be a result of climate change over CA. It will make a significant contribution to the sustainable development and construction of a national society, the economy, environment and ecology for CA.

In this study, the weather research and forecasting (WRF) model (Skamarock et al. 2005) was used to conduct dynamic downscaling of reanalysis datasets and GCM outputs with different LSM parameterizations to produce high- resolution climate data for the CA. The impacts of different land surface process parameterizations on the results of dynamic downscaling were analyzed, and the results of the dynamic downscaling were compared to the outputs of Version 4 of the Community Climate System Model (CCSM4). Dynamic downscaling and the CCSM4 model were then used to project the mean and extreme climate change of the CA under two different representative concentration pathways (RCPs) in the future. 
The remainder of this paper is organized as follows: Sect. 2 describes the use of RCMs, the design of the dynamic downscaling experiments, the data and method used in this study. Section 3 compares observed data to the results of historical simulations by the dynamic downscaling experiments and CCSM4, while Sect. 4 describes the projections by the GCM and dynamic downscaling experiments. The discussions and main conclusions of this study are presented in Sect. 5.

\section{Model, data, and experimental design}

\subsection{Model and data}

The WRF model, developed by the National Center for Atmospheric Research (NCAR) has become a widely used medium-range weather forecast model and RCM in climate change research (Leung et al. 2006), and has been selected as one of the RCMs for the international Coordinated Regional Climate Downscaling Experiment (CORDEX). In this study, Version 3.7.1 of the WRF model was used to conduct all the dynamic downscaling experiments. This consisted of downscaling reanalysis datasets and GCM results, which produced higher-resolution data regarding the historical and future climates of the CA.

The initial and boundary conditions of the dynamic downscaling experiments were obtained from the CCSM4 model in CMIP5 (historical dataset: 1985-2005, future projections: RCP4.5 and RCP8.5, 2006-2100) and the ERA-Interim reanalysis dataset for 1985-2005. For all models and experiments, the results of the first ensemble member (r1i1p1) were used in this study. It has been demonstrated that the CCSM4 model is fit for simulating the spatio-temporal characteristics of the Asian climate (Xu et al. 2017). Based on the analysis in the previous section, it was found that the CCSM4 model is highly effective in simulating the climate of the CA. Furthermore, bias-corrected CMIP5 CESM Data for WRF has improved results in dynamical downscaling applications (Bruyère et al. 2014) (https://rda.ucar.edu/datas ets/ds316.1/). The ERA-Interim reanalysis dataset, which was obtained from the European Centre for Medium-Range Weather Forecasts (ECMWF) is an improved version of the ERA-40 dataset. The data has a horizontal resolution of $0.75^{\circ} \times 0.75^{\circ}$, and is one of the most reliable and widely used reanalysis datasets for studying the climate change characteristics in complex surface feature regions (Wang and Zeng 2012; Gao et al. 2014) (https://www.ecmwf.int/en/forecasts/ datasets/reanalysis-datasets).

Global temperature and precipitation datasets from the Climate Prediction Center (CPC) were used as observations to evaluate the results of the GCM and dynamic downscaling experiments. The resolution of this data is $0.5^{\circ} \times 0.5^{\circ}$, and it included measurements of minimum and maximum daily temperatures and daily precipitation (Chen et al. 2002). The CPC dataset has been developed by the American National Oceanic and Atmospheric Administration (NOAA) using the optimal interpolation of quality-controlled gauge records of the Global Telecommunication System (GTS) network (Fan and Van den Dool 2008). In this study, mean daily temperature was obtained by taking the arithmetic mean of the minimum and maximum temperature.

For comparison convenience, both the simulation and observational data were regrided to $0.5^{\circ} \times 0.5^{\circ}$ resolution by using bilinear interpolation method. The analyses are based on the end of the century (2080-2099) under RCP4.5 and RCP8.5, relative to the present day period of 1986-2005 to focus on the high end of the range of future changes in dynamic downscaling experiments and CCSM4 outputs. The climate indices that were analyzed in this study are shown in Table 1. The temperature-related indices include the annual maxima of daily maximum temperatures (TXX), annual minima of daily minimum temperatures (TNN), summer days (SU), and frost days (FD). While TXX and SU represent extreme heat events, TNN and FD represent extreme cold events. The precipitation-related indices include the number of days with $\geq 10 \mathrm{~mm}$ of precipitation (R10mm), the annual total precipitation of days with $\geq 1 \mathrm{~mm}$ of precipitation (PRCPTOT), the density of precipitation on days with $\geq 1 \mathrm{~mm}$ of precipitation (SDII), and the maximum consecutive number of dry days (CDD). The eight climate indices including some extremes indices are defined by the
Table 1 Description of the eight chosen climate indices including some extreme indicators

\begin{tabular}{lll}
\hline Indices & Definition & Units \\
\hline TXX & The annual maxima of daily maximum & ${ }^{\circ} \mathrm{C}$ \\
TNN & The annual minima of daily minimum & ${ }^{\circ} \mathrm{C}$ \\
SU & Number of days with minimum temperature greater than $25^{\circ} \mathrm{C}$ & Days \\
FD & Number of days with minimum temperature less than $0{ }^{\circ} \mathrm{C}$ & Days \\
PRCPTOT & Annual total precipitation $(\mathrm{R} \geq 1 \mathrm{~mm})$ & $\mathrm{mm}$ \\
SDII & Average rainfall from wet days & $\mathrm{mm} /$ day \\
R10mm & Annual count of days when rainfall $\geq 10 \mathrm{~mm}$ & Days \\
CDD & Maximum number of consecutive days with $\mathrm{RR}<1 \mathrm{~mm}$ & Days \\
\hline
\end{tabular}


expert team on climate change detection and indices (ETCCDI) (Karl et al. 1999; Frich et al. 2002; Zhang et al. 2011; Shi et al. 2017) and were selected to illustrate model performance in simulating the climate and its extremes. Two-tailed Student's $t$ test was used to calculate significance for the climate change over the CA.

\subsection{Experimental design}

All the dynamic downscaling experiments conducted by WRF were double-nested (Fig. 1). The domain 01 covers most regions of Asia, and the center is at the point $\left(46.5^{\circ} \mathrm{N}, 70^{\circ} \mathrm{E}\right.$ ). There are 60 (longitudinal) $\times 42$ (latitudinal) grid points in domain 01 with the horizontal resolution of $90 \mathrm{~km}$. The center point of domain 02 is the same as domain 01 , and there are 124 (longitudinal) $\times 82$ (latitudinal) grid points in domain 02 with the horizontal resolution of $30 \mathrm{~km}$. The vertical levels were set to 30 with the model top at $50 \mathrm{mb}$ in all the dynamic downscaling experiments. The initial and lateral boundary conditions of the dynamic downscaling experiments were taken from the ERA-Interim reanalysis datasets and the CCSM4 model outputs, respectively, and the lateral boundary conditions and sea surface temperature (SST) were updated every $6 \mathrm{~h}$ in the simulation.

The fine spatial resolution of RCMs is useful to improve model performance in resolving both the spatial pattern and magnitude of mean and extreme climate (Gao et al. 2017). The vertical resolution of the WRF model is also very important (Zhang et al. 2015); however, its impact on simulation performance is complex because there does not appear to be a direct relationship between vertical resolution and model performance. The impact of vertical resolution is multifaceted and based on many physical mechanisms that

(a)

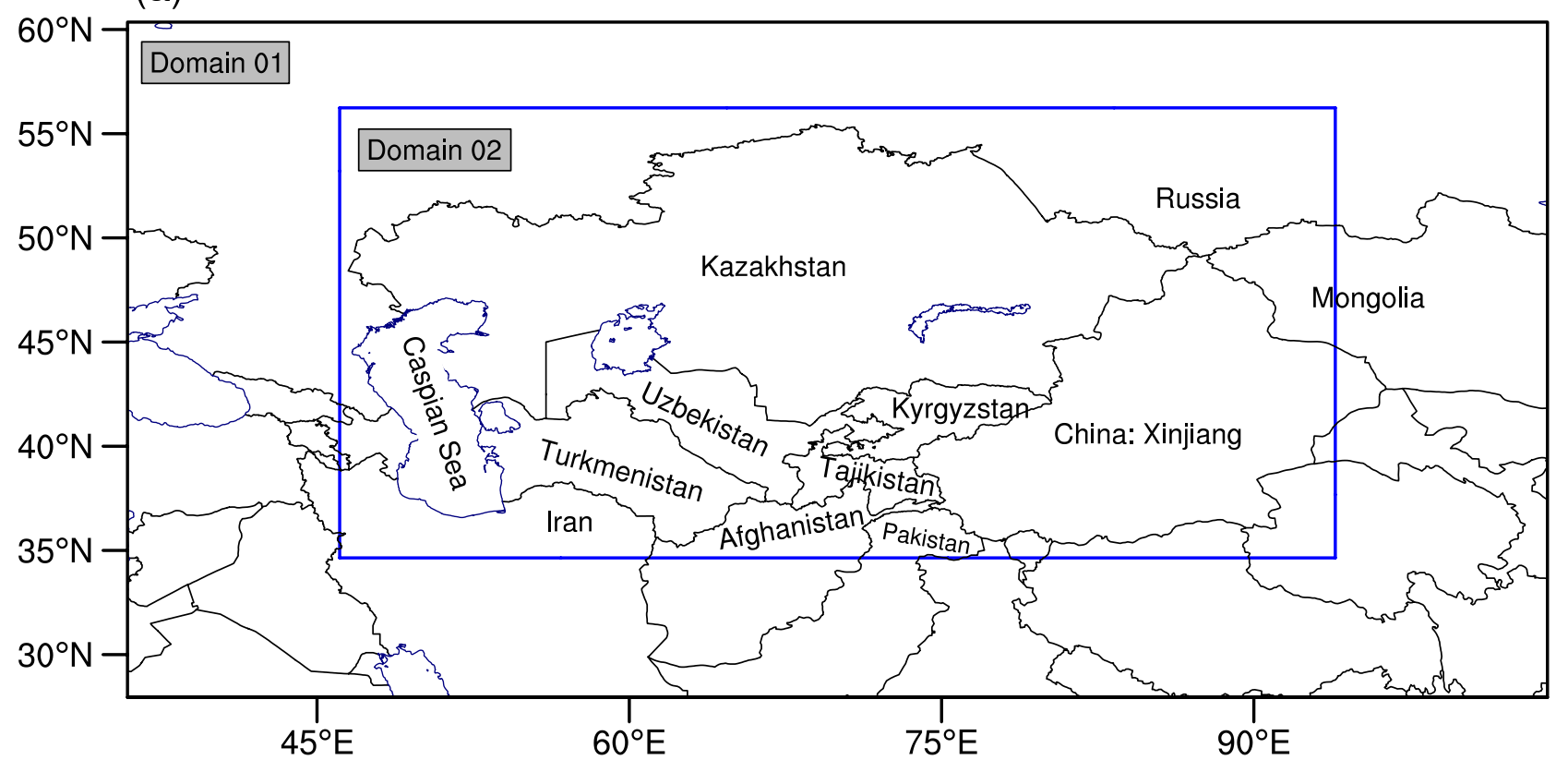

(b)

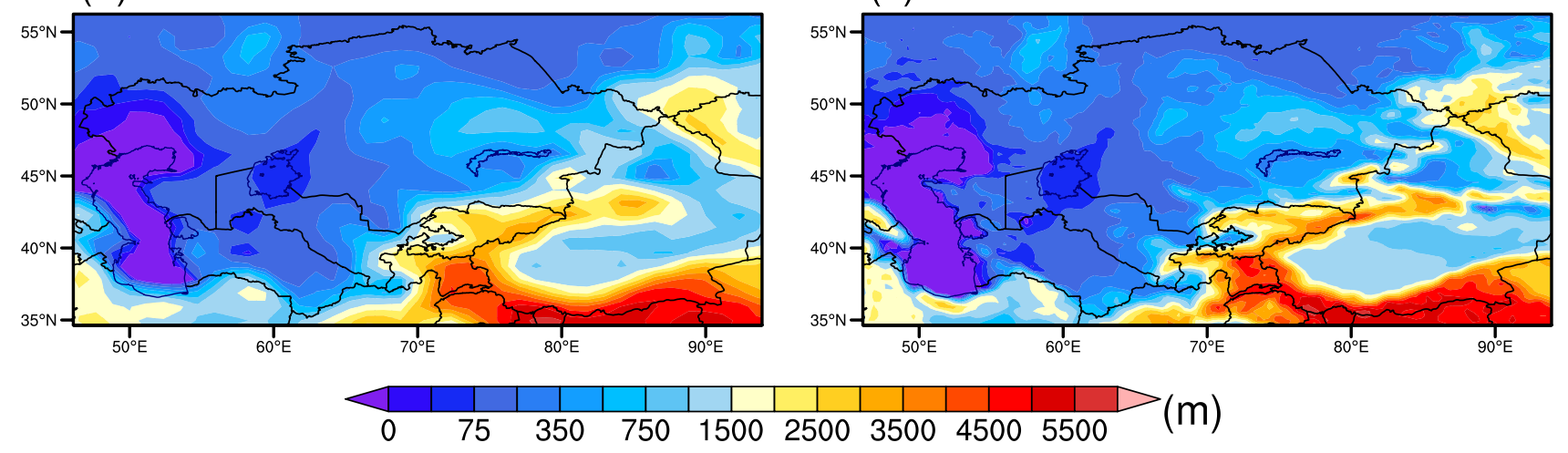

Fig. 1 Locations of the WRF domains (a). The horizontal resolution of domain 01 is $90 \mathrm{~km}$, and the resolution of domain 02 is $30 \mathrm{~km}$. Elevation resolutions are shown for domain $01(\mathbf{b})$ and domain $02(\mathbf{c})$ 
are challenging to calculate. Consequently, the same vertical resolution is used in both domains.

Eight dynamic downscaling experiments were conducted, including four historical experiments and four projection experiments (Table 2). For all historical experiments, simulations were initialized at 0000 UTC on January 1, 1985 and ended at 2300 UT on December 31, 2005. All the simulations for projection experiments were initialized at 0000 UTC on January 1, 2006 and ended at 2300 UTC on December 31,2100 . The first year for each time slice is considered to be spin-up and not included in the analysis.

The parameterizations of the dynamic downscaling experiment differed in the land surface processes. Two different LSMs were employed for this purpose, the Noah (WRFE1, WRFC1 and WRFR1) (Tewari et al. 2004) and the Noah-MP (WRFE2, WRFC2 and WRFR2) (Niu et al. 2011) schemes. The Noah scheme was derived from the Oregon State University (OSU) LSM, and it increases the soil moisture stratification to four layers, which enables soil moisture forecasting in four layers of soil below the surface. The Noah scheme also accounts for physical processes such as snow accumulation and soil freezing, thus facilitating the forecasting of these processes. The effects of single-layer canopies and single-layer snow cover are also considered in this scheme. In models using the Noah scheme, land-atmosphere heat and humidity exchange coefficients are obtained by calculating soil thermal conductivity and soil diffusivity. Noah-MP is an improved version of the Noah scheme, and it is a rather unique WRF LSM because it has multiple parameterization options. Like Noah, Noah-MP accounts for the vegetation canopy, but it also separates the canopy from the ground. In summary, Noah-MP generally improves upon the Noah scheme in its handling of vegetation dynamics, snow accumulation calculations, and hydrological processes (Yang et al. 2011; Chen et al. 2014). The remaining parameterizations of the dynamic downscaling experiments are as follows: the CAM shortwave scheme and longwave scheme (Collins et al. 2004), the WRF single-moment 3-class (WSM3) microphysics scheme (Hong et al. 2004), the Grell-Freitas cumulus parameterization scheme (Grell and Freitas 2014), and the YSU boundary layer scheme (Hong and Lim 2006).

\section{Model validation}

Model simulations from 1986 to 2005 are compared with corresponding observations in the CA.

\subsection{Temperature and temperature-related indices}

From Fig. 2a, we can see that the highest ANN temperature of the CA (greater than $16{ }^{\circ} \mathrm{C}$ ) is located in the southerncentral Turkmenistan and eastern Iran, whereas the lowest ANN temperature (lower than $-6{ }^{\circ} \mathrm{C}$ ) is located in the Tibetan Plateau. CCSM4 model overestimates ANN temperatures in the northwestern CA, but underestimates ANN temperatures in the Tibetan Plateau and Tajikistan, with the maximum bias approximately $5{ }^{\circ} \mathrm{C}$ (Fig. 2d). In contrast, WRFE1 underestimates the ANN temperature of the northwestern CA, and the maximum bias appeared in the Tibetan Plateau and Tajikstan (Fig. 2g). The results of WRFE2 are superior to WRFE1, in particular for regions such as the Tibetan Plateau, the northern Xinjiang, and the rest of China (Fig. 2j). In comparison to the CCSM4 model, there are significant improvements for the simulation of annual mean temperature over the $\mathrm{CA}$ in the dynamic downscaling experiments, especially for WRFE2 and WRFC2 (Fig. 2j, p). Similar to the annual mean temperature, the maximum DJF temperature also occurs in southern-central Turkmenistan and the eastern Iran. The minimum DJF temperature for the CA is in the Tibetan Plateau and the western Mongolia (Fig. 2b). The simulation of DJF temperatures by the CCSM4 model also results in significant bias in the northwestern and southeastern CA, which it is consistent with the simulation of ANN temperature (Fig. 2e). The DJF temperature simulated by the WRFE1 and WRFC1 experiments are significantly different from the results of the CCSM4 model because of the significant cold bias in the northwestern CA (Fig. 2h, n). The results of WRFE2 and WRFC2 are little better than the
Table 2 The names, initial field data, and land surface process parameterizations of the dynamic downscaling experiments

\begin{tabular}{lllll}
\hline Type of experiment & Name & Driving data & Experimental scenario & $\begin{array}{l}\text { Land surface } \\
\text { process param- } \\
\text { eterization }\end{array}$ \\
\hline Historical experiments & WRFE1 & ERA-Interim & Historical & Noah \\
& WRFE2 & ERA-Interim & Historical & Noah-MP \\
& WRFC1 & CMIP5 & Historical & Noah \\
& WRFC2 & CMIP5 & Historical & Noah-MP \\
Projection experiments & WRFR1 & CMIP5 & RCP4.5/RCP8.5 & Noah \\
& WRFR2 & CMIP5 & RCP4.5/RCP8.5 & Noah-MP \\
\hline
\end{tabular}


(a) Mean temp. in ANN, 1986-2005, CPC, ${ }^{\circ} \mathrm{C}$

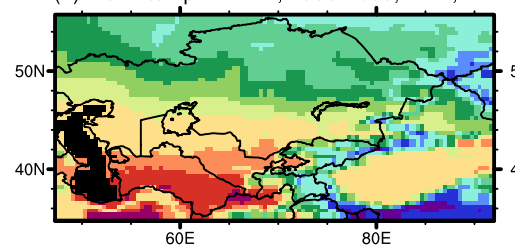

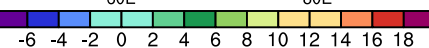

(d) Temp. diff., ANN, 1986-2005, CCSM $4,{ }^{\circ} \mathrm{C}$

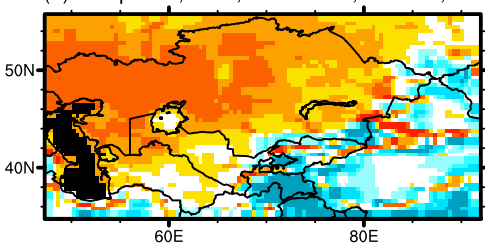

(g) Temp. diff., ANN, 1986-2005, WRFE1, ${ }^{\circ} \mathrm{C}$

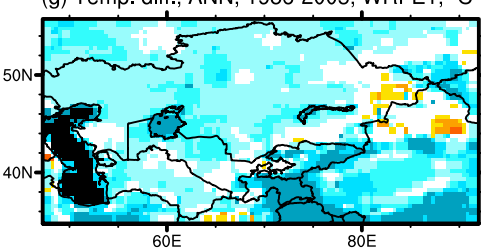

(j) Temp. diff., ANN, 1986-2005, WRFE2, ${ }^{\circ} \mathrm{C}$

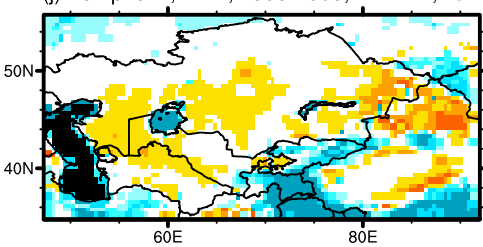

(m) Temp. diff., ANN, 1986-2005, WRFC1, ${ }^{\circ} \mathrm{C}$

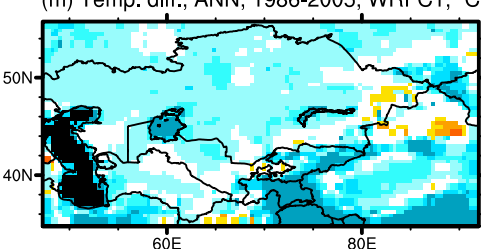

(p) Temp. diff., ANN, 1986-2005, WRFC2, ${ }^{\circ} \mathrm{C}$

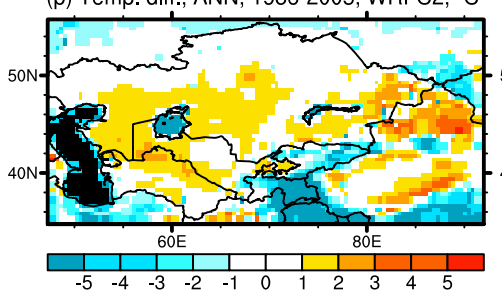

(b) Mean temp. in DJF, 1986-2005, CPC, ${ }^{\circ} \mathrm{C}$

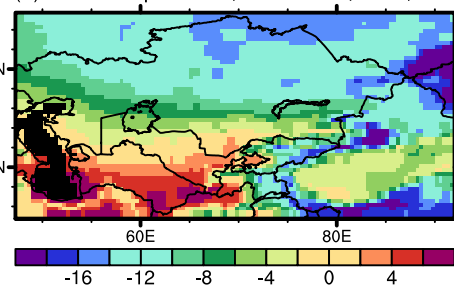

(e) Temp. diff., DJF, 1986-2005, CCSM4, ${ }^{\circ} \mathrm{C}$

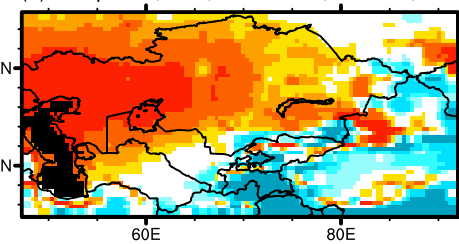

(h) Temp. diff., DJF, 1986-2005, WRFE1, ${ }^{\circ} \mathrm{C}$

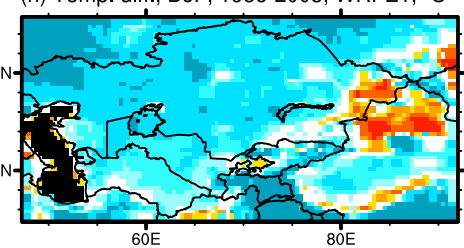

(k) Temp. diff., DJF, 1986-2005, WRFE2, ${ }^{\circ} \mathrm{C}$

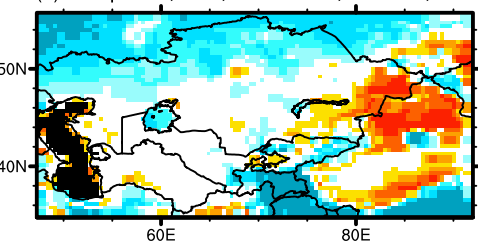

(n) Temp. diff., DJF, 1986-2005, WRFC $1,{ }^{\circ} \mathrm{C}$

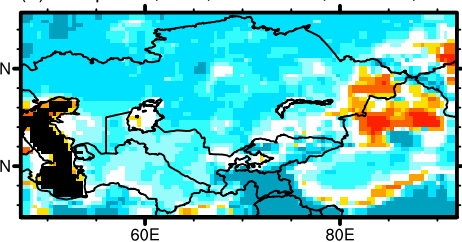

(q) Temp. diff., DJF, 1986-2005, WRFC2, ${ }^{\circ} \mathrm{C}$

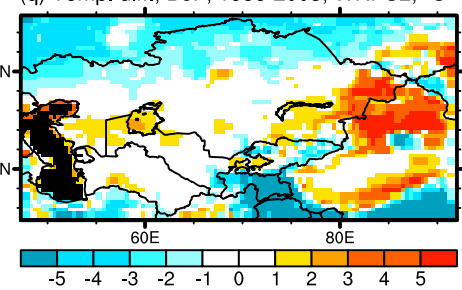

(c) Mean temp. in JJA, 1986-2005, CPC, ${ }^{\circ} \mathrm{C}$
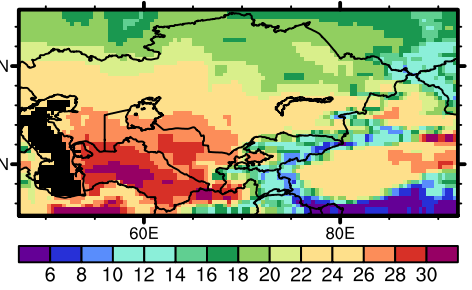

(f) Temp. diff., JJA, 1986-2005, CCSM4, ${ }^{\circ} \mathrm{C}$

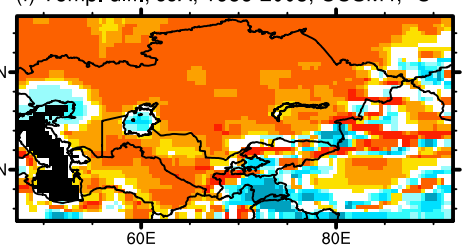

(i) Temp. diff., JJA, 1986-2005, WRFE1, ${ }^{\circ} \mathrm{C}$

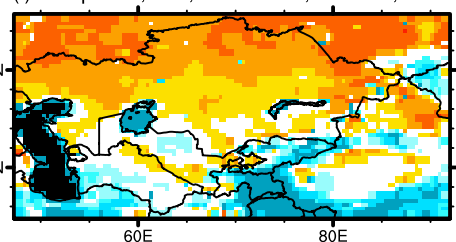

(I) Temp. diff., JJA, 1986-2005, WRFE2, ${ }^{\circ} \mathrm{C}$

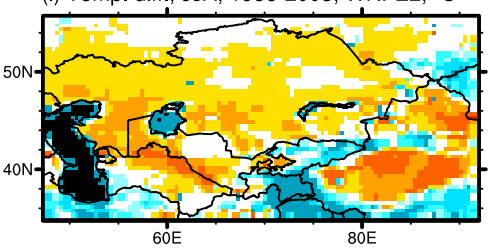

(o) Temp. diff., JJA, 1986-2005, WRFC $1,{ }^{\circ} \mathrm{C}$

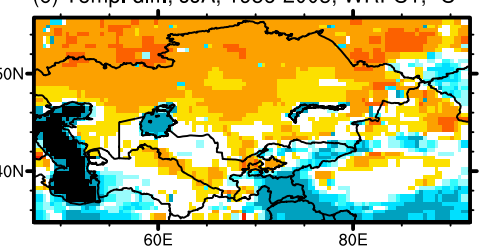

(r) Temp. diff., JJA, 1986-2005, WRFC2, ${ }^{\circ} \mathrm{C}$

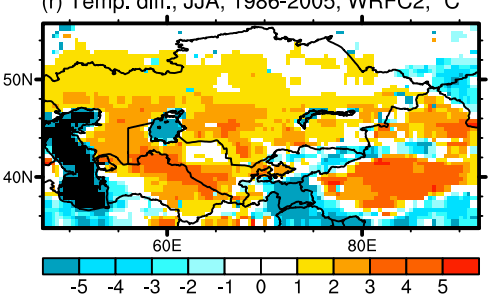

Fig. 2 The observed mean temperature and the modeled bias in ANN (a, d, g, j, m, p), DJF (b, e, h, k, n, q) and JJA (c, f, i, l, o, r) of 19862005 over CA and model bias (unit: $\left.{ }^{\circ} \mathrm{C}\right)$. (d-f: CCSM4; g-i: WRFE1; j-l: WRFE2; m-o: WRFC1; p-r: WRFC2)

results of the CCSM4 model, WRFE1 and WRFC1 (Fig. 2k, q). Unlike the ANN and DJF results, the JJA results of the WRFE1 and WRFC1 experiments are more consistent with the CCSM4 model. In the spatial distribution of JJA temperatures simulated by the WRFE2 and WRFC2 experiments, warm biases are centered in central CA and Xinjiang, and cold biases are centered in the Tibetan Plateau and Turkmenistan. Compared to the results of CCSM4, WRFE1, and WRFC1, the WRFE2 and WRFC2 experiments present more congruency with observation for the simulation of JJA temperature in the northern CA (Fig. 2f, i, 1, o, r).

The probability distributions of temperature biases from CCSM4 and the dynamic downscaling are compared (Fig. 3a-c). For ANN temperatures (Fig. 3a), most of grid points in the CCSM4 output predominantly display warm biases, with only a few grid points showing cold biases. The biases of the CCSM4 model range between -8 and $6{ }^{\circ} \mathrm{C}$, and the bias from $25 \%$ of the grid points is between 2 and 

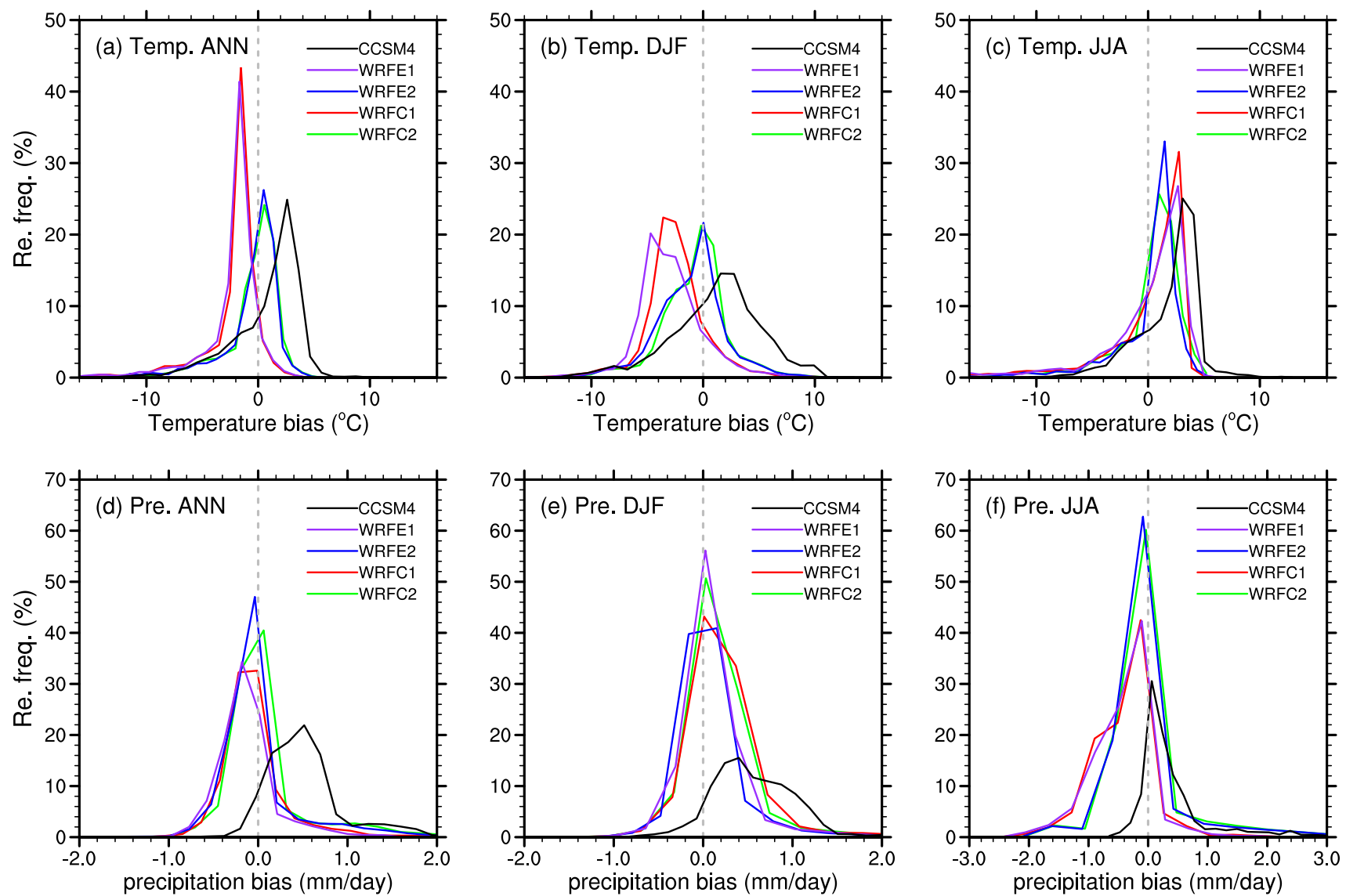

Fig. 3 Relative frequency (\%) of temperature bias is shown in the 1st row: ANN (a), DJF (b), JJA (c). Precipitation bias is shown in the 2nd row: ANN (d), DJF (e), JJA (f) Results for ANN (1st column),

DJF (2nd column), and JJA (3rd column) are shown over CA, as derived from the CCSM4 model and dynamic downscaling simulations (unit: temperature ${ }^{\circ} \mathrm{C}$, precipitation $\mathrm{mm} /$ day)

$4{ }^{\circ} \mathrm{C}$. Most of the grid points in the WRFE1 and WRFC1 results display cold biases, and only a few of the grid points show warm biases. The biases of the WRFE1 and WRFC1 range between -10 and $4{ }^{\circ} \mathrm{C}$, and more than $40 \%$ of the grid points have cold biases of approximately $-1{ }^{\circ} \mathrm{C}$. The grid points in WRFE2 and WRFC2 experiments are almost evenly divided between cold and warm biases, with most of the bias being approximately $0{ }^{\circ} \mathrm{C}$, which accounts for $25 \%$ of all the grid points in the WRFE2 and WRFC2 experiments. The JJA and DJF temperatures of the CCSM4 model are predominantly overestimated, which is similar to the ANN temperature. The maximum warm bias is approximately $10{ }^{\circ} \mathrm{C}$. The JJA and DJF temperatures obtained from the WRFE1 and WRFC1 experiments are not consistent with each other, because the DJF and JJA results are dominated by cold biases with a maximum of $-10^{\circ} \mathrm{C}$ and warm biases with a maximum of $5{ }^{\circ} \mathrm{C}$, respectively. The simulations for JJA and DJF temperatures are consistent with the ANN temperature in WRFE2 and WRFC2, and the biases are small and close to $0{ }^{\circ} \mathrm{C}$ shown by most of the grid points (Fig. 3b, c). A Taylor diagram is a concise statistical summary of how well different patterns match each other in terms of the spatial correlation coefficient (COR), root-mean-square error (RMSE), and ratio of variances (Taylor et al. 2012). Taylor diagrams of the temperature and precipitation simulated by the CCSM4 model and dynamic downscaling experiments are presented in Fig. 4. For the ANN mean temperature of the CA (Fig. 4a), the COR of CCSM4 is less than 0.9, whereas the CORs are greater than 0.9 in the four dynamic downscaling experiments and standard deviations are all close to 1.25. For the DJF temperature, the COR of CCSM4 model is lower than that for ANN temperature, while all the CORs from the four dynamic downscaling experiments are at least 0.9, which is higher than the CCSM4 model. Furthermore, the standard deviations of the dynamically downscaled DJF temperatures are smaller than the dynamically downscaled ANN temperatures. However, for the JJA temperature, the CCSM4 results are superior to those obtained from dynamic downscaling, with their standard deviation close to 1.0. Nonetheless, these results show that the CORs of the WRFE2 (WRFC2) results are significantly larger than those of the WRFE1 (WRFC1) results. 
(a) Temperature

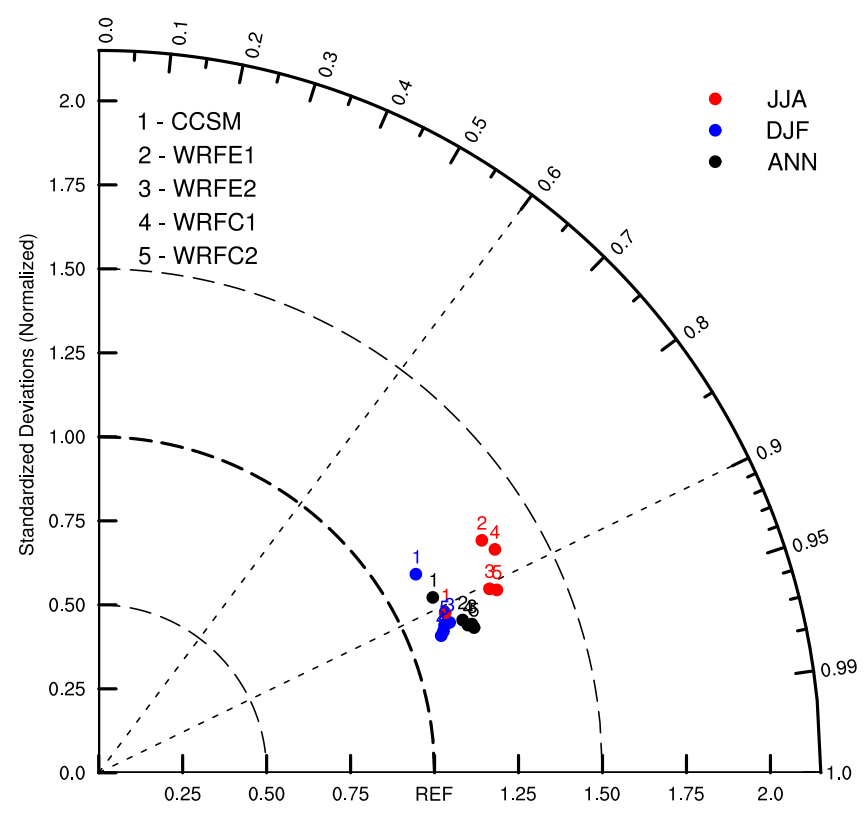

(b) Precipitation

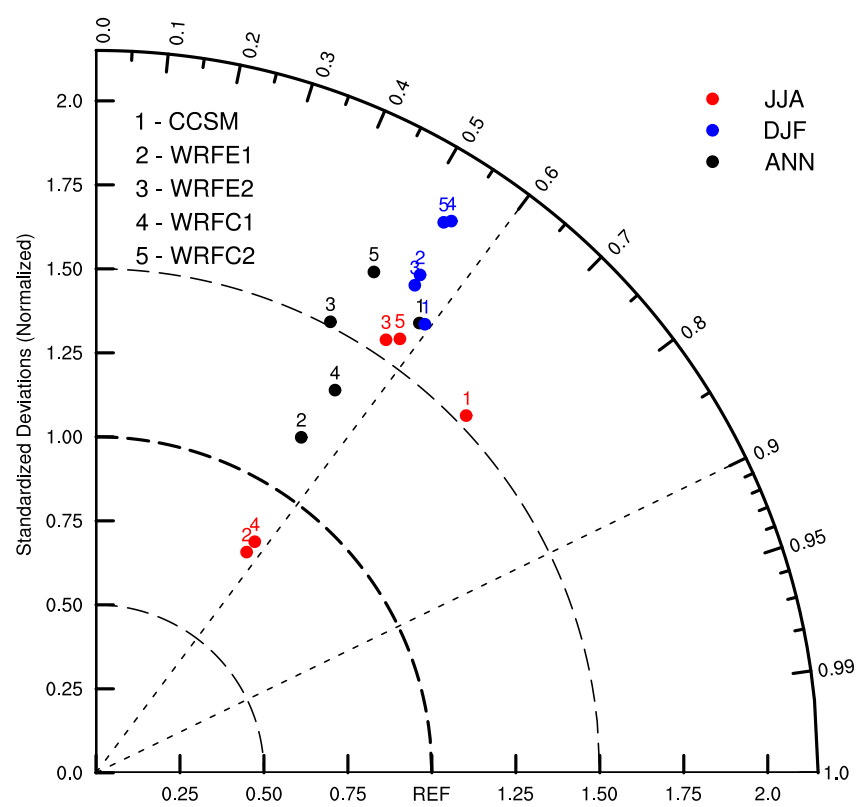

Fig. 4 Taylor diagram for temperature (a) and precipitation (b) in ANN, DJF and JJA over the CA

Overall, compared to the CCSM4 model, the dynamic downscaling of reanalysis data and CCSM4 data result in significant improvements for the simulation of temperature. The results of the dynamic downscaling have smaller biases and higher CORs. Significant differences are also presented between the dynamic downscaling experiments, because the results of the WRFE2 and WRFC2 experiments are better than those of the WRFE1 and WRFC1 experiments. Based on these results, the Noah-MP scheme is superior to the Noah scheme as an LSM for the simulation of the CA temperatures by the dynamic downscaling. Furthermore, limited high resolution datasets obtained from observation stations will result in error, and will present challenges for model validation (Wu and Gao 2013).

Figure 5a shows that the high-value area of SU is located in the southeastern region of Turkmenistan, where the maximum SU is greater than 180 days. In the higher latitudes of the CA and the Tibetan Plateau, the minimum SU is less than 5 days. The CCSM4 model and dynamic downscaling experiments are able to reproduce most of the spatial features of the observed SU, but with significant biases in the magnitude and the area with high-value. The CCSM4, WRFE1, and WRFC1 experiments underestimate values of the index and the area with high-value, whereas the WRFE2 and WRFC2 experiments only overestimate the area with high-value (Fig. 5e, i, m, q, u). When comparing the probability distribution of model biases (Fig. 6), it was found that the results of WRFE2 and WRFC2 are superior to those of CCSM4, WRFE1, and WRFC1, because the former set of results contain a greater number of grid points, with biases close to 0 day. Furthermore, WRFE2 and WRFC2 are the only simulations with spatial CORs greater than 0.90 and RMSEs lower than 25 days (Table 3). The high-value area of the observed TXX index is located in central Turkmenistan, where the maximum temperature reached $44.0^{\circ} \mathrm{C}$. The minimum TXX value is less than $24.0^{\circ} \mathrm{C}$ that occurred in the Tibetan Plateau (Fig. 5b). The CCSM4, WRFE2, WRFC1, and WRFC2 results overestimate the area with high-value (Fig. 5f, n, r, v), whereas the WRFE1 result is closer to the observation (Fig. 5j). The results of CCSM4, WRFE2, WRFC1, and WRFC2 are dominated by significant positive biases, whereas the WRFE1 results are with biases close to $0.0{ }^{\circ} \mathrm{C}$ (Fig. 6b). Furthermore, the WRFE1 result presents the COR of greater than 0.90 and a relatively small RMSE. In contrast to TXX index, the observed FD index of the CA is significantly and positively correlated with latitude and altitude. The high-value area of FD is located in the Tibetan Plateau, reaching 300 days. The low-value area is located in the southwestern CA, where the minimum FD value is approximately 20 days (Fig. $5 \mathrm{c}$ ). The CCSM4 model produces a reliable simulation of the observed spatial distribution of FD over the CA (Fig. 5g). The four dynamic downscaling experiments also reproduce the distribution features of FD over the CA (Fig. 5k, o, s, w). For model biases of FD, the results of the CCSM4 model are dominated by negative biases because the CCSM4 model overestimates the area of low-value region in the southwestern CA. Instead, the dynamic downscaling experiments mainly display positive biases (Fig. 6c). The positive biases of the WRFE1 and WRFC1 experiments are large because these 
(a) SU, 1986-2005, CPC, days

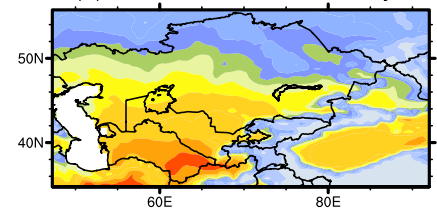

(e) SU, 1986-2005, CCSM4, days

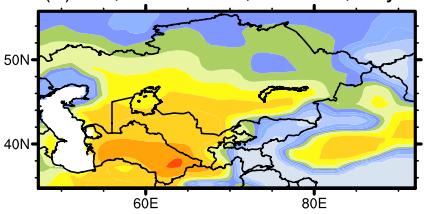

(i) SU, 1986-2005, WRFE1, days

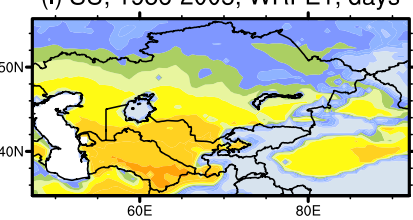

(m) SU, 1986-2005, WRFE2, days

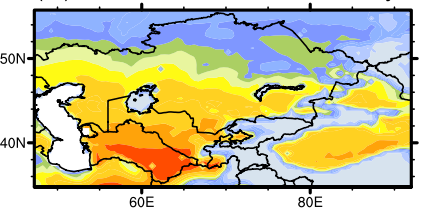

(q) SU, 1986-2005, WRFC1, days

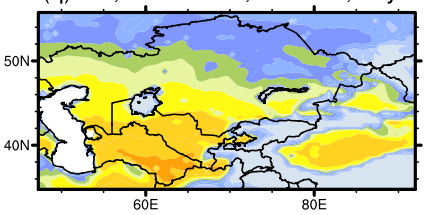

(u) SU, 1986-2005, WRFC2, days

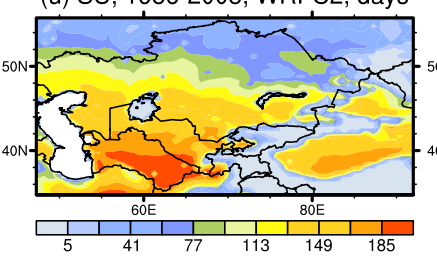

(b) TXX, 1986-2005, CPC, ${ }^{\circ} \mathrm{C}$

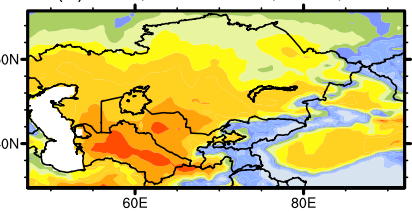

(f) TXX, 1986-2005, CCSM4, days (c) FD, 1986-2005, CPC, days

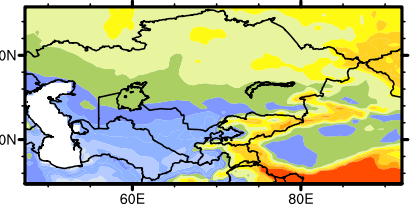

(g) FD, 1986-2005, CCSM4, days

(d) TNN, 1986-2005, CPC, ${ }^{\circ} \mathrm{C}$

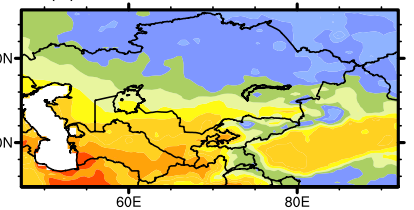

(h) TNN, 1986-2005, CCSM $4,{ }^{\circ} \mathrm{C}$

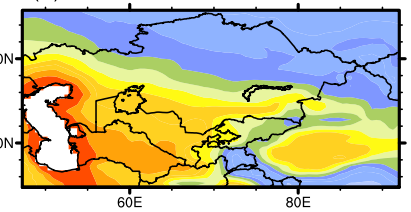

(I) TNN, 1986-2005, WRFE1, ${ }^{\circ} \mathrm{C}$

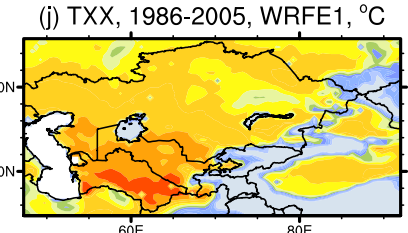

(n) TXX, 1986-2005, WRFE2, ${ }^{\circ} \mathrm{C}$

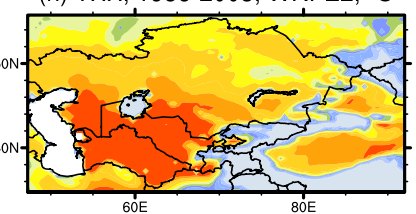

(r) TXX, 1986-2005, WRFC $1,{ }^{\circ} \mathrm{C}$

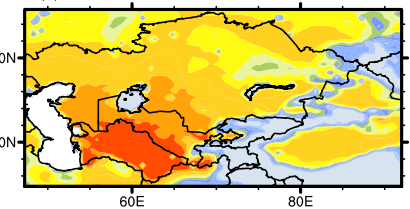

(v) TXX, 1986-2005, WRFC2, ${ }^{\circ} \mathrm{C}$

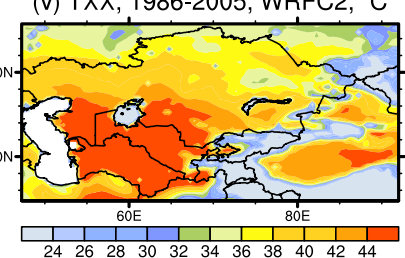

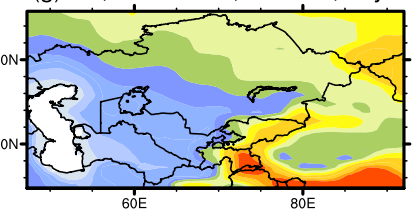

(k) FD, 1986-2005, WRFE1, days

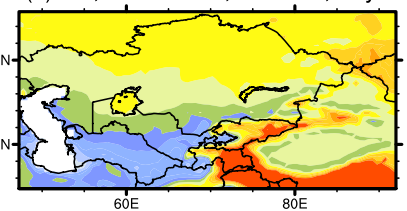

(o) FD, 1986-2005, WRFE2, days

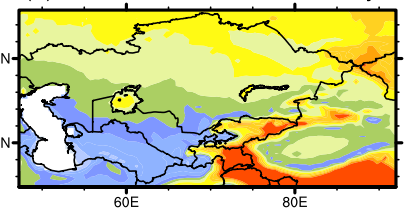

(s) FD, 1986-2005, WRFC1, days

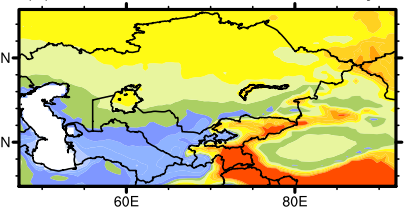

(w) FD, 1986-2005, WRFC2, days

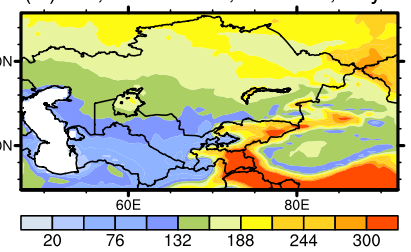

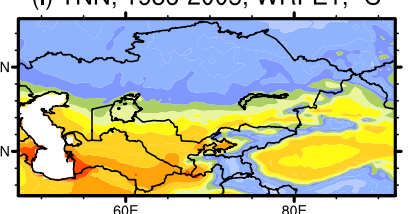

(p) TNN, 1986-2005, WRFE2, ${ }^{\circ} \mathrm{C}$

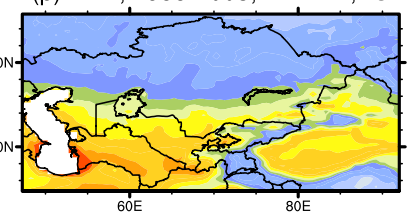

(t) TNN, 1986-2005, WRFC $1,{ }^{\circ} \mathrm{C}$

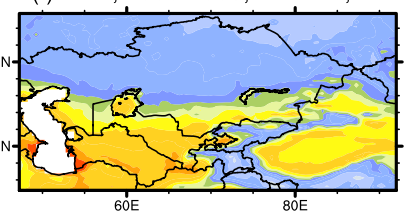

(x) TNN, 1986-2005, WRFC2, ${ }^{\circ} \mathrm{C}$

Fig. 5 The observed and simulated temperature-related extreme indices of SU (1st column, days), TXX (2nd column, $\left.{ }^{\circ} \mathrm{C}\right), \mathrm{FD}(3 \mathrm{rd}$ column, days) and TNN (4th column, ${ }^{\circ}$ ) of 1986-2005 over CA. (a-d: Observation; e-h: CCSM4; i-l: WRFE1; m-p: WRFE2; q-t: WRFC1; u-x: WRFC2)

models have underestimated the area of the low value region in the southwestern CA, but overestimates the area of the high value region in the northern CA. Through comparing the spatial CORs and RMSEs of the simulations (Table 3), it is found that the results of the dynamic downscaling were better than the CCSM4 model for the simulation of FD over the CA, particularly for the WRFE2 and WRFC2 models. The high-value area of TNN is located around the southern Caspian Sea, where the maximum TNN is greater than $-8.0^{\circ} \mathrm{C}$, and the low-value area of TNN is located in northeastern CA and the Tibetan Plateau, where the minimum TNN is less than $-40.0^{\circ} \mathrm{C}$. The distribution of TNN values simulated by the CCSM4 model is similar to that observed. The low-value region is accurately reproduced by the CCSM4 model, but there are significant biases around the southern Caspian Sea and Xinjiang. The four dynamic downscaling experiments succeed in reproducing the spatial patterns of trend. Figure $6 \mathrm{~d}$ shows that the biases of the CCSM4 model and dynamic downscaling experiments are dominated by significant negative biases that becomes larger after the dynamic downscaling. This is because the dynamic downscaling experiments overestimate the low-value region in the northern CA. It is found that the dynamic downscaling experiments have higher CORs than the CCSM4 model but also larger RMSE values. Therefore, the improvement of the dynamic downscaling over the CCSM4 model can't be fully demonstrated. 

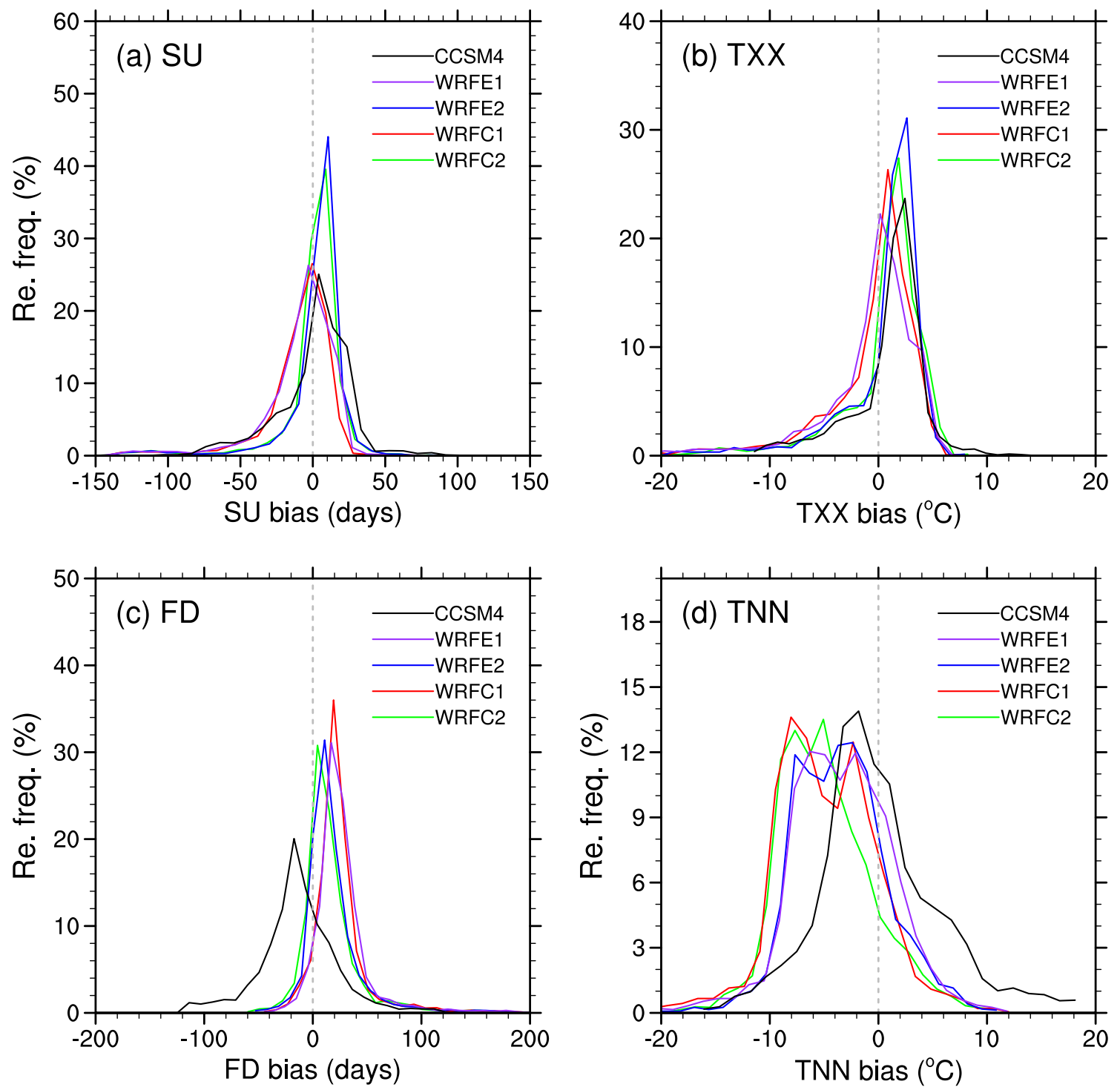

Fig. 6 Relative frequency (\%) of biases for temperature-related indices: SU (a), TXX (b), FD (c) and TNN (d) over the CA simulated by CCSM4 and dynamic downscaling simulations derived by CCSM4

Table 3 Spatial correlation coefficients (CORs) and RMSEs of temperature-related climate indices, between each of the CCSM4, WRFE1, WRFC1, WRFE2, WRFC2 simulations and observation

\begin{tabular}{|c|c|c|c|c|c|c|c|c|c|c|}
\hline & \multicolumn{5}{|l|}{ COR } & \multicolumn{5}{|l|}{ RMSE } \\
\hline & CCSM4 & WRFE1 & WRFE2 & WRFC1 & WRFC2 & CCSM4 & WRFE1 & WRFE2 & WRFC1 & WRFC2 \\
\hline SU & 0.88 & 0.88 & 0.91 & 0.89 & 0.92 & 26.26 & 28.21 & 24.37 & 27.60 & 24.30 \\
\hline TXX & 0.88 & 0.91 & 0.89 & 0.88 & 0.91 & 3.66 & 3.88 & 4.27 & 4.69 & 4.23 \\
\hline FD & 0.86 & 0.92 & 0.92 & 0.92 & 0.91 & 38.44 & 39.15 & 33.97 & 37.54 & 32.57 \\
\hline TNN & 0.85 & 0.91 & 0.91 & 0.91 & 0.90 & 5.75 & 5.68 & 5.48 & 6.71 & 6.54 \\
\hline
\end{tabular}

the CA have an ANN daily precipitation less than $1 \mathrm{~mm}$, especially for southern-central Xinjiang, where the ANN daily precipitation is less than $0.4 \mathrm{~mm}$ (Fig. 7a). The DJF daily precipitation is less than $1 \mathrm{~mm}$ in most parts of the CA. Xinjiang has the lowest level of DJF daily precipitation 
(a) Pre. ANN, 1986-2005, CPC, mm/day

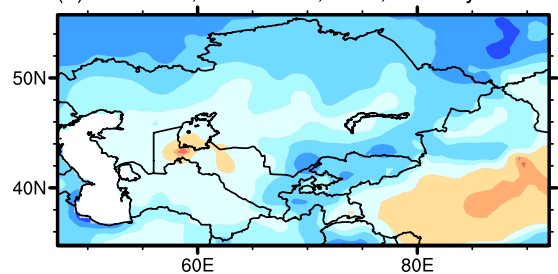

(d) Pre., ANN, 1986-2005, CCSM4, mm/day

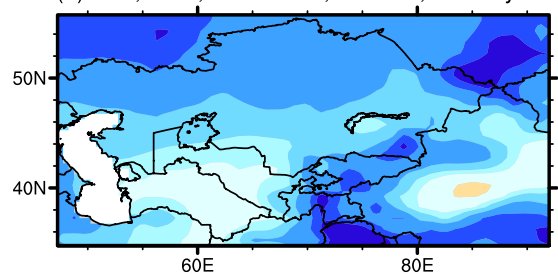

(g) Pre., ANN, 1986-2005, WRFE1, mm/day

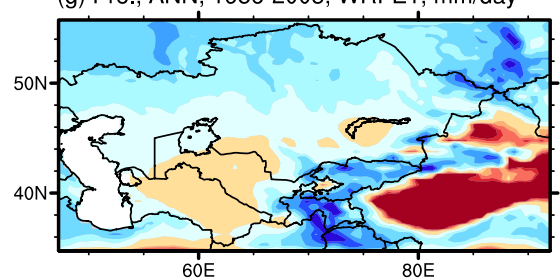

(j) Pre., ANN, 1986-2005, WRFE2, mm/day

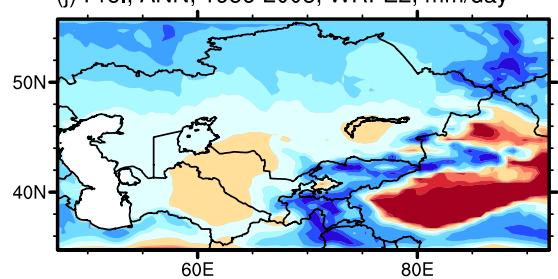

(m) Pre., ANN, 1986-2005, WRFC1, mm/day

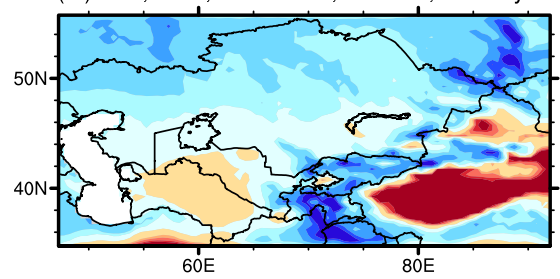

(p) Pre., ANN, 1986-2005, WRFC2, mm/day

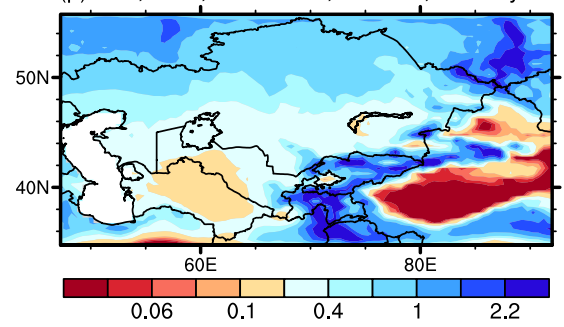

(b) Pre. DJF, 1986-2005, CPC, mm/day

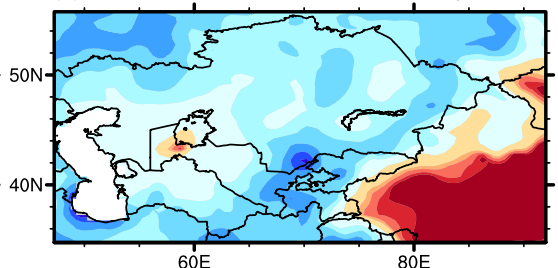

(e) Pre., DJF, 1986-2005, CCSM4, mm/day

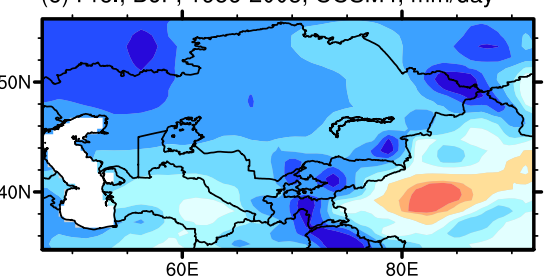

(h) Pre., DJF, 1986-2005, WRFE1, mm/day

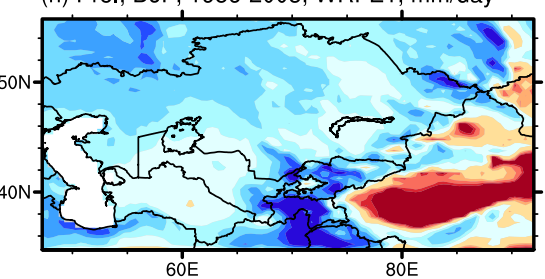

(k) Pre., DJF, 1986-2005, WRFE2, mm/day

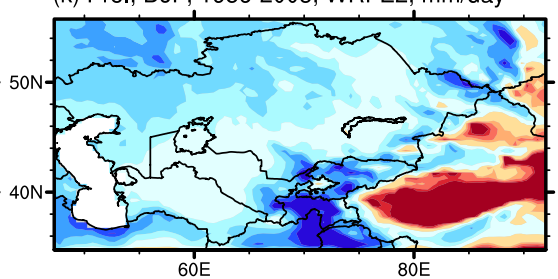

(n) Pre., DJF, 1986-2005, WRFC1, mm/day

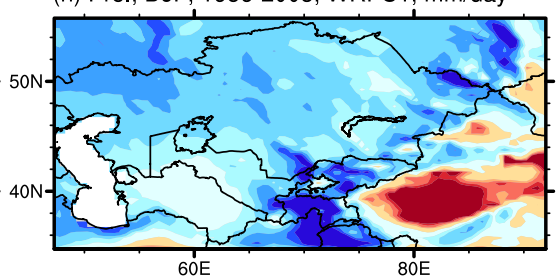

(q) Pre., DJF, 1986-2005, WRFC2, mm/day

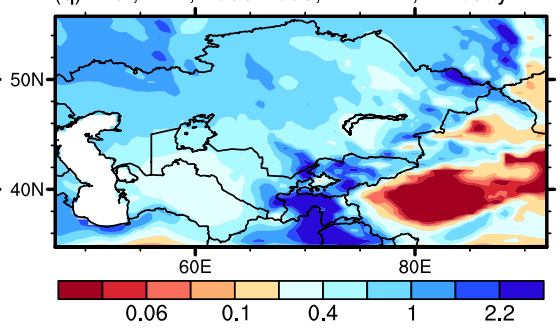

(c) Pre. JJA, 1986-2005, CPC, mm/day

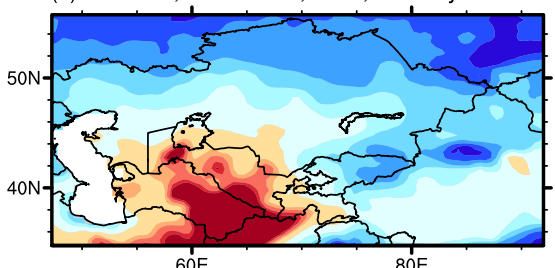

(f) Pre., JJA, 1986-2005, CCSM4, mm/day

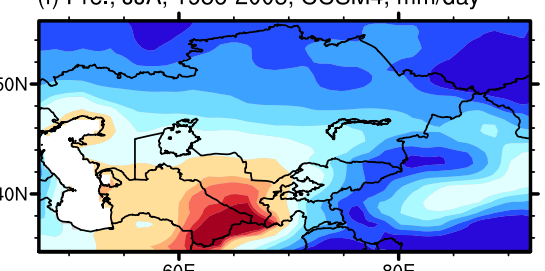

(i) Pre., JJA, 1986-2005, WRFE1, mm/day

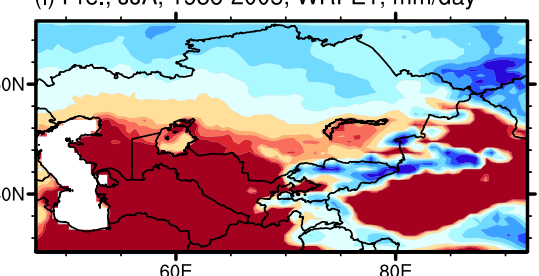

(I) Pre., JJA, 1986-2005, WRFE2, mm/day

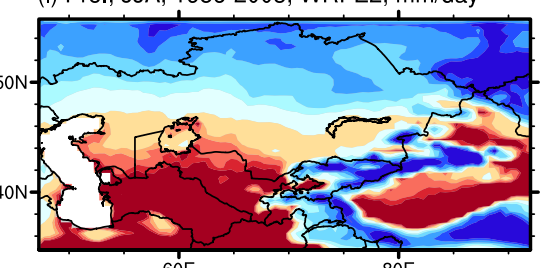

(o) Pre., JJA, 1986-2005, WRFC1, mm/day

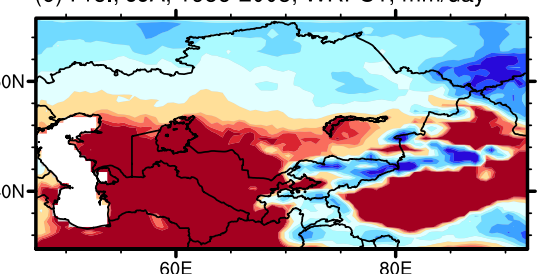

(r) Pre., JJA, 1986-2005, WRFC2, mm/day

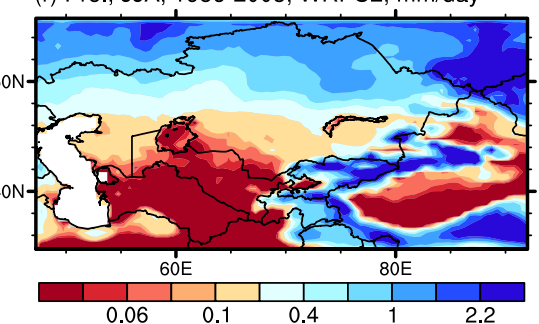

Fig. 7 The observed and simulated mean precipitation in ANN (a, d, g, j, m, p), DJF (b, e, h, k, n, q) and JJA (c, f, i, l, o, r) of 1986-2005 over the CA (unit: mm/day). (d-f: CCSM4; $\mathbf{g}-\mathbf{i}$ : WRFE1; j-l: WRFE2; m-o: WRFC1; p-r: WRFC2)

in the CA, at less than $0.1 \mathrm{~mm}$ (Fig. 7b). During summer, precipitation is most abundant in the northern $\mathrm{CA}$, and the maximum daily precipitation can reach $2 \mathrm{~mm}$ (Fig. 7c). The results of the CCM4 model shows significant positive biases in the ANN, DJF and JJA daily precipitation of the $\mathrm{CA}$ and an abundance of precipitation is presented in the high latitudes. The maximum daily precipitation simulated by the CCSM4 model is $2 \mathrm{~mm}$, which is significantly higher than the observation. For the DJF precipitation, the CCSM4 model overestimates the daily precipitation of high-latitude regions in the CA and Xinjiang. The most notable feature in the CCSM4-simulation of JJA daily precipitation is the quite 
small low-precipitation zone in the southeastern Turkmenistan (Fig. 7d-f). In the dynamic downscaling experiments, there is a similar spatial distribution of the precipitation simulated by the WRFE1 and WRFC1 over the CA, and the high ANN daily precipitation is presented by WRFE1 and WRFC1 in the higher latitudes that is shown by observation. The spatial distribution of DJF daily precipitation obtained by the WRFE1 and WRFC1 experiments for the CA are largely consistent with the observation. Although the extreme low-precipitation zone in Xinjiang is slightly smaller in the simulations. However, the JJA daily precipitations simulated by the WRFE1 and WRFC1 experiments also exhibit significant biases, as the high-precipitation zone in the northern CA is absent, and the area of the low-precipitation zone in the southeastern Turkmenistan is overestimated. Furthermore, the WRFE1 and WRFC1 results show a notable negative bias in Xinjiang. The results of the WRFE2 and WRFC2 experiments are largely consistent with those obtained by the WRFE1 and WRFC1 experiments. The main differences between the dynamic downscaling experiments are that the distributions of JJA precipitation simulated by WRFE2 and WRFC2 are closer to the observed distribution (Fig. 71, r). Although the WRFE2 and WRFC2 results also overestimate the size of the low-precipitation zone in Turkmenistan and underestimate the precipitation of Xinjiang, these results remain superior to the WRFE1 and WRFC1 results relative to the observation.

In Fig. 3, it is shown that the ANN daily precipitations of the CCSM4 model are dominated by positive biases. The biases at most of the CCSM4 grid points are approximately $0.5 \mathrm{~mm}$ with the maximum bias being $2.0 \mathrm{~mm}$. The bias probability distributions of the dynamic downscaling experiments are largely identical; in all the four experiments, more than $30 \%$ of the grid points have biases between -0.2 and $0.0 \mathrm{~mm}$. Therefore, the results of the dynamic downscaling experiments are significantly better than those of the CCSM4 model (Fig. 3d). The CCSM4 model predominantly displays positive biases in DJF, whereas the dynamic downscaling experiments have biases close to $0.0 \mathrm{~mm}$. Hence, dynamic downscaling has significantly improved the accuracy of the DJF precipitation simulation (Fig. 3e). However, the CCSM4 model does outperform the dynamic downscaling experiments in the simulation of JJA precipitation in the CA (Fig. 3f). A Taylor diagram (Fig. 4b) of the CCSM4 and dynamic downscaling simulations of daily precipitation characterizes the differences between the observed and simulated ANN, DJF, and JJA daily precipitation data in the CA. In terms of ANN daily precipitation, the CCSM4 model has a COR close to 0.6, which is larger than the CORs of the four dynamic downscaling experiments. Of the various simulations, the WRFE1 and WRFC1 experiments have standard deviations that are closest to 1 . In terms of the spatial distribution of DJF and JJA daily mean precipitation in the CA, the results of the dynamic downscaling experiments do not show a significant improvement over the CCSM4 model, but there is a small improvement for ANN precipitation. The effects of different LSMs on dynamic downscaling are also insignificant.

The observed R10mm index do not show any significant features in its distribution other than two significant highvalue areas (Fig. 8). The high-value area is located in the northwestern and northeastern CA, where the maximum $\mathrm{R} 10 \mathrm{~mm}$ reaches 10 days. The most significant and largest low-value region is located in the southern-central Xinjiang, where the minimum R10mm is less than 2 days (Fig. 8a). The CCSM4 model represents the high-value area in the northeastern and northwestern CA, but overestimates the maximum value in the northeastern CA (Fig. 8e). For the dynamic downscaling experiments, the high-value area in the northeastern and northwestern CA is absent, and there are significant positive biases located in the northwestern China and its surroundings. There are no significant differences between the results of the four dynamic downscaling experiments (Fig. 8i, m, q, u). Figure 9a demonstrates that the model biases of the CCSM4 model and dynamic downscaling experiments are not significantly different from each other. The CORs and RMSEs shown in Table 4 also confirm that the dynamic downscaling did not significantly improve the simulation of $\mathrm{R} 10 \mathrm{~mm}$. The spatial distribution of the observed PRCPTOT is similar to the R10mm index, with high-value area locates in the northeastern and northwestern $\mathrm{CA}$ and a low-value area in the southern-central Xinjiang. The maximum PRCPTOT in the high-value area is larger than $550 \mathrm{~mm}$, whereas the minimum PRCPTOT in the lowvalue area is less than $50 \mathrm{~mm}$ (Fig. 8b). There are significant positive biases shown by the simulation of the CCSM4 model over the CA. Significant positive biases are presented for the high-value area in the northeastern and northwestern CA, central Xinjiang and the Tibetan Plateau (Fig. 8f). The results of the four dynamic downscaling experiments are similar to each other, and they generally underestimate the area of the high-value centers in the northeastern and northwestern CA, and overestimate PRCPTOT values around the northwestern boundary of China. There are no significant differences between the RCM results (Fig. 8j, n, r, v). Most of the grid points in the CCSM4 results show positive biases, with the maximum bias reaching $600 \mathrm{~mm}$ (Fig. 9b). The dynamic downscaling results are dominated by negative biases, but many grid points in these results have biases close to $0 \mathrm{~mm}$. The spatial COR of the CCSM4 results is 0.58 and the dynamic downscaling results generally presents a COR that is lower than 0.50. However, the RMSE of the CCSM4 model is greater than $200 \mathrm{~mm}$, whereas the dynamic downscaling results generally present lower RMSEs. The observed SDII index is less in the eastern-central parts of the CA but larger in the western CA. The high-value area 


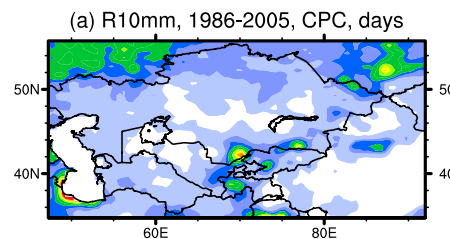

(e) R10mm, 1986-2005, CCSM4, days
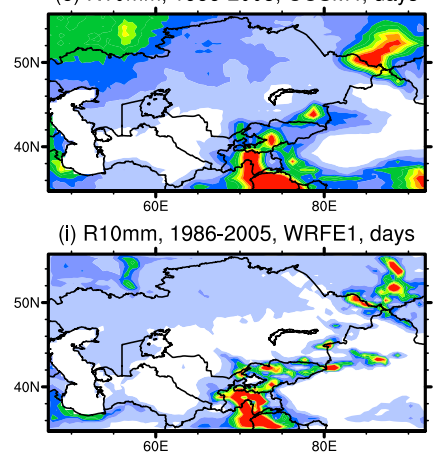

(m) R10mm, 1986-2005, WRFE2, days

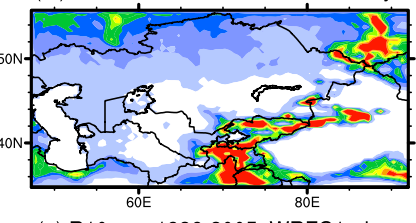

(q) R10mm, 1986-2005, WRFC1, days

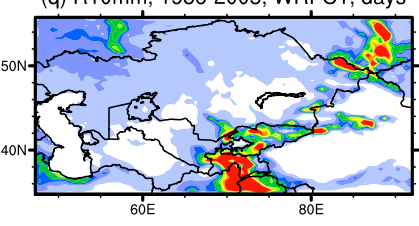

(u) R10mm, 1986-2005, WRFC2, days

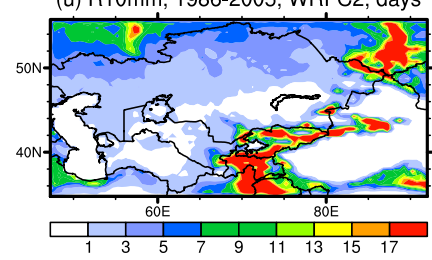

(b) PRCPTOT, 1986-2005, CPC, mm

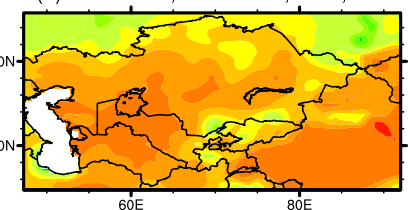

(f) PRCPTOT, 1986-2005, CCSM4, mm

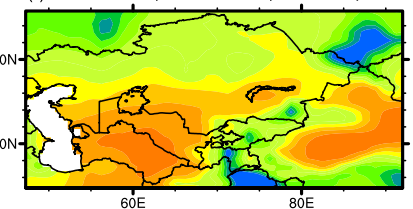

(j) PRCPTOT, 1986-2005, WRFE1, mm

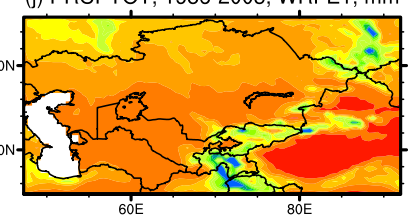

(n) PRCPTOT, 1986-2005, WRFE2, mm

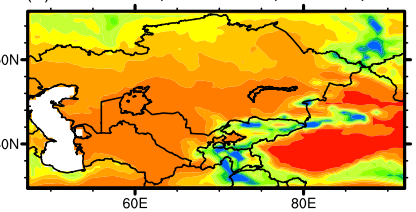

(r) PRCPTOT, 1986-2005, WRFC1, mm

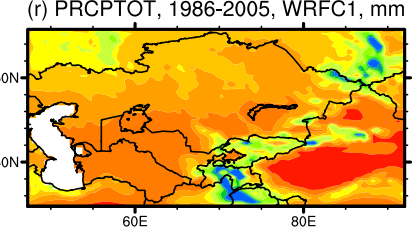

(v) PRCPTOT, 1986-2005, WRFC2, mm

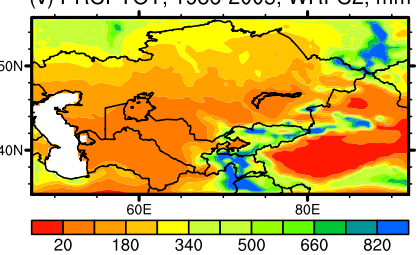

(c) SDII, 1986-2005, CPC, mm/day

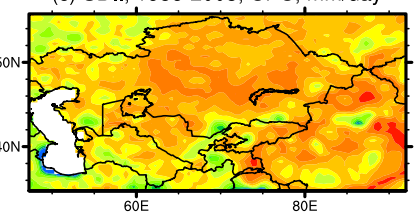

(g) SDII, 1986-2005, CCSM4, mm/day

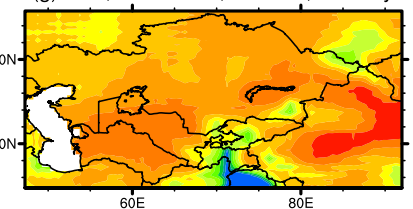

(k) SDII, 1986-2005, WRFE1, mm/day

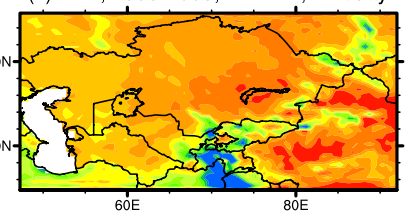

(o) SDII, 1986-2005, WRFE2, mm/day

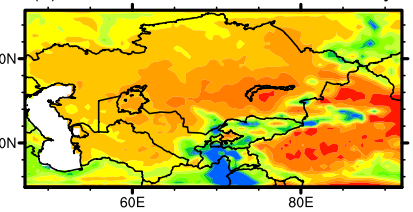

(s) SDII, 1986-2005, WRFC1, mm/day

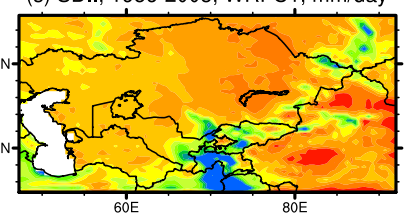

(w) SDII, 1986-2005, WRFC2, mm/day

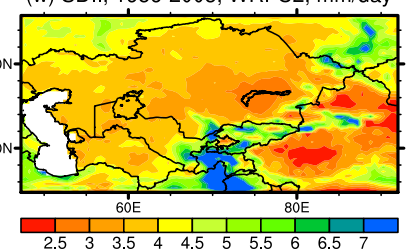

(d) CDD, 1986-2005, CPC, days

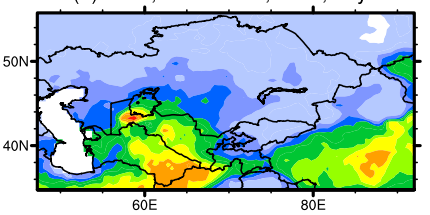

(h) CDD, 1986-2005, CCSM4, days

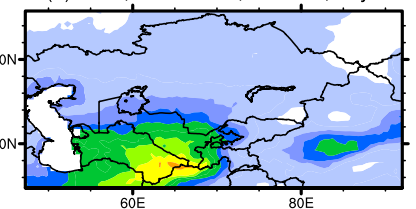

(I) CDD, 1986-2005, WRFE1, days

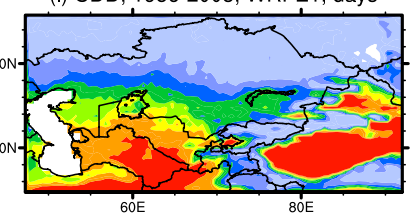

(p) CDD, 1986-2005, WRFE2, days

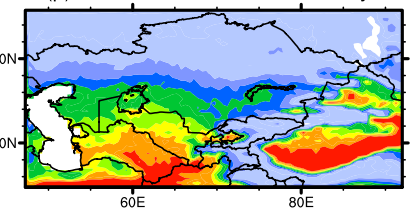

(t) CDD, 1986-2005, WRFC1, days

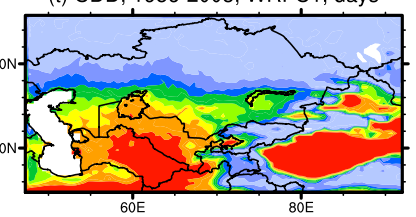

(x) CDD, 1986-2005, WRFC2, days

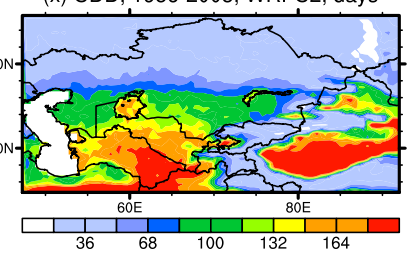

Fig. 8 Similar to Fig. 5, but for precipitation-related indices: R10mm (1st column, days), PRCPTOT (2nd column, mm), SDII (3rd column, mm/ day) and CDD (4th column, days). (a-d: Observation; e-h: CCSM4; i-l: WRFE1; m-p: WRFE2; q-t: WRFC1; u-x: WRFC2)

of SDII is located in the southwestern Caspian Sea, where SDII reaches $6 \mathrm{~mm} /$ day. There is no significant lower SDII area in the CA (Fig. 8c). The CCSM4 model and dynamic downscaling experiments generally succeed in reproducing the spatial distribution of SDII over the CA. However, the simulated results show an anomalous high-value area in the southern-central CA that is absent in the observed data. The differences between CCSM4 and dynamic downscaling are insignificant (Fig. 8g, k, o, s, w). The probability distributions of bias produce by the CCSM4 and dynamic downscaling simulations are also similar to each other. The biases range between -4 and $4 \mathrm{~mm} /$ day, and approximately $30 \%$ of their grid points produce biases that are close to $0 \mathrm{~mm} /$ day (Fig. 9c). The CCSM4 and dynamic downscaling results also present similar spatial CORs, of approximately 0.6 , and the RMSE of the CCSM4 is less than the dynamic downscaling (Table 4). The feature shown by CDD is high in the south and low in the north. The high-value regions include the southeastern Uzbekistan, southeastern Turkmenistan, and southern Xinjiang, and the maximum CDD in these regions is more than 132 days (Fig. 8d). Figure 8h shows that there are significant negative biases in the CDD simulated by the CCSM4 model, because the CCSM4 model underestimates both the area and magnitude of the high-value area in the southern CA. The results of the dynamic downscaling experiments are similar and could reproduce the spatial features shown by the observed CDD. However, the dynamic downscaling overestimates the magnitude and area with two 

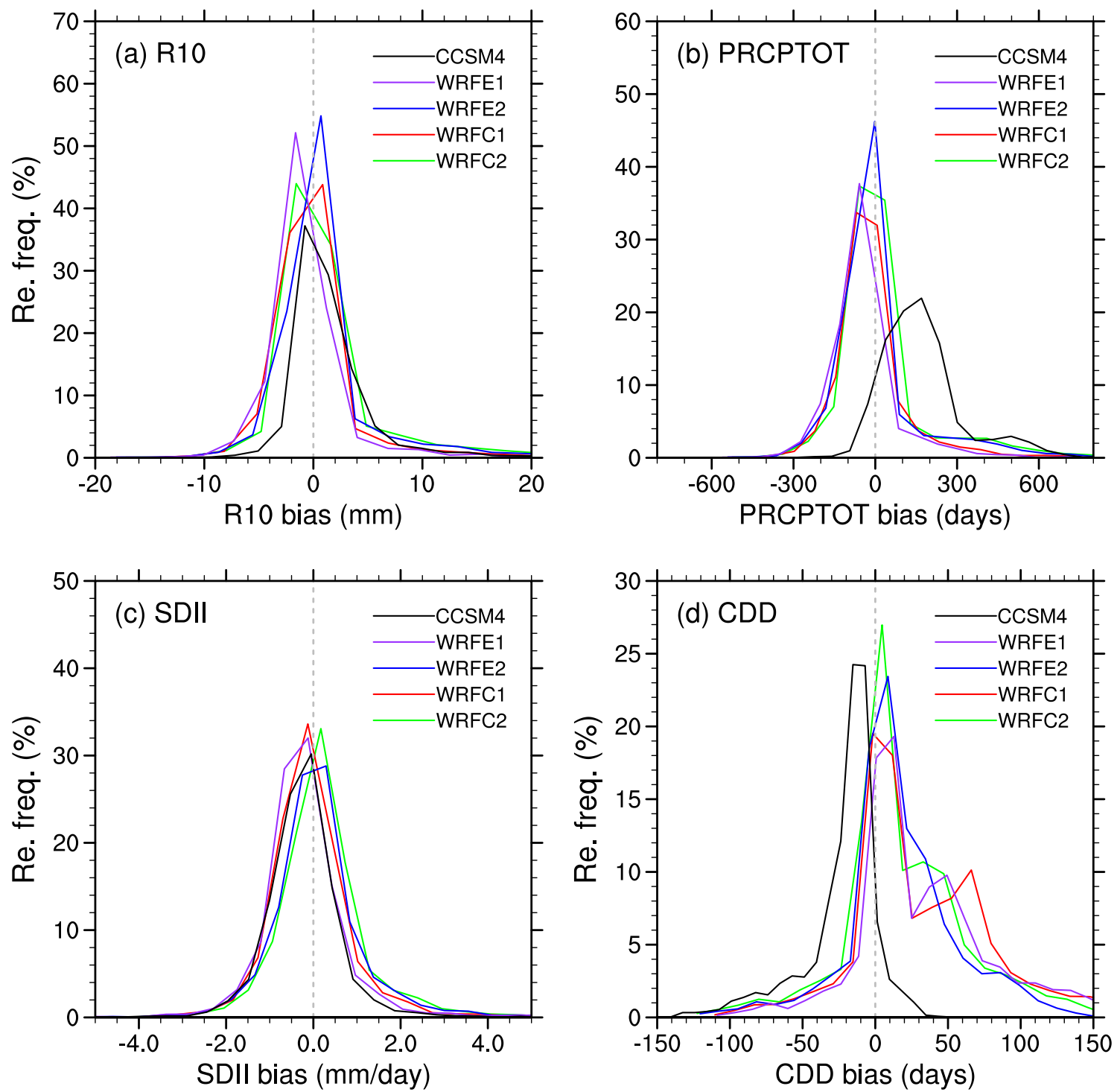

Fig. 9 Similar to Fig. 6, but for precipitation-related indices of R10mm, PRCPTOT, SDII and CDD

Table 4 Similar to Table 3, but for precipitation-related indices

\begin{tabular}{|c|c|c|c|c|c|c|c|c|c|c|}
\hline & \multicolumn{5}{|l|}{ COR } & \multicolumn{5}{|l|}{ RMSE } \\
\hline & CCSM4 & WRFE1 & WRFE2 & WRFC1 & WRFC2 & CCSM4 & WRFE1 & WRFE2 & WRFC1 & WRFC2 \\
\hline $\mathrm{R} 10 \mathrm{~mm}$ & 0.47 & 0.33 & 0.32 & 0.36 & 0.34 & 5.05 & 4.47 & 5.79 & 5.05 & 6.66 \\
\hline PRCPTOT & 0.58 & 0.49 & 0.43 & 0.50 & 0.45 & 244.54 & 142.76 & 178.46 & 152.64 & 198.32 \\
\hline SDII & 0.42 & 0.43 & 0.38 & 0.42 & 0.39 & 0.91 & 1.07 & 1.15 & 1.12 & 1.22 \\
\hline CDD & 0.71 & 0.72 & 0.71 & 0.72 & 0.70 & 36.35 & 58.10 & 44.49 & 63.29 & 50.11 \\
\hline
\end{tabular}

high-value. The differences among the dynamic downscaling experiments are insignificant (Fig. 81, p, t, x). Comparing the bias probability distributions of the simulations revealed that the CCSM4 model predominantly exhibits negative biases and has many grid points with the biases between -100 and 0 . The dynamic downscaling experiments are dominated by positive biases with their CDD biases ranging between 0 and 150 (Fig. 9d). This is mainly because the dynamic downscaling experiments overestimate the magnitude and area with high-value in the CA. Based on the spatial CORs 
of the CCSM4 and dynamic downscaling simulations respect to observed result, it is found that the differences between CCSM4 and dynamic downscaling of the simulations for climatology pattern are insignificant, and the COR is around 0.7. The CCSM4 model produces the smallest RMSE between the simulated results. Therefore, dynamic downscaling experiments do not improve the simulation of CDD significantly.

Overall, the CCSM4 model and dynamic downscaling experiments are able to represent the spatial distribution of climate indices in the CA, although temperaturerelated indices are usually simulated more accurately than
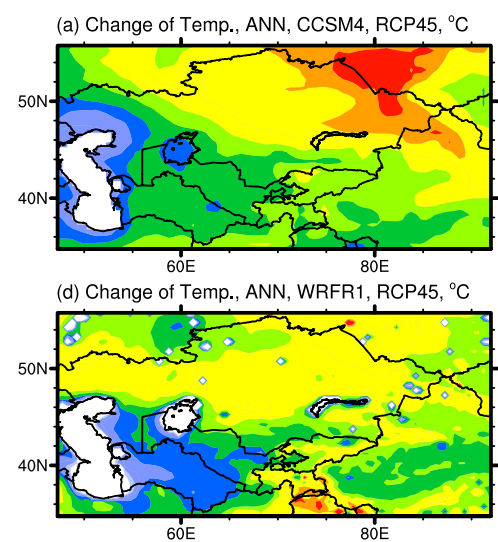

(g) Change of Temp., ANN, WRFR2, RCP45, ${ }^{\circ} \mathrm{C}$

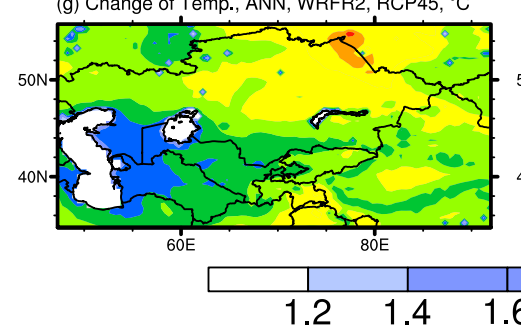

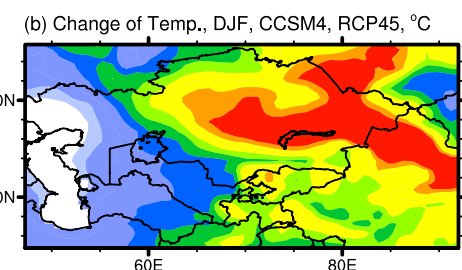

(e) Change of Temp., DJF, WRFR1, RCP $45,{ }^{\circ} \mathrm{C}$

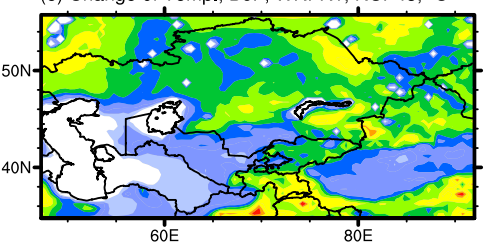

(h) Change of Temp., DJF, WRFR2, RCP $45,{ }^{\circ} \mathrm{C}$

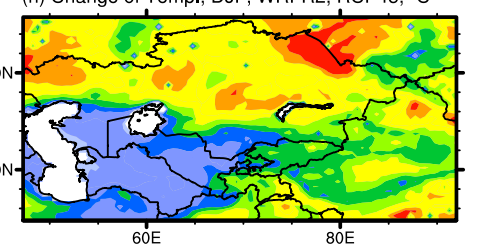

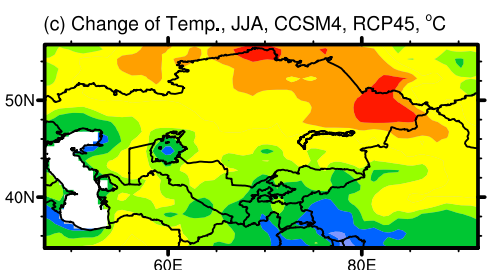

(f) Change of Temp., JJA, WRFR1, RCP $45,{ }^{\circ} \mathrm{C}$

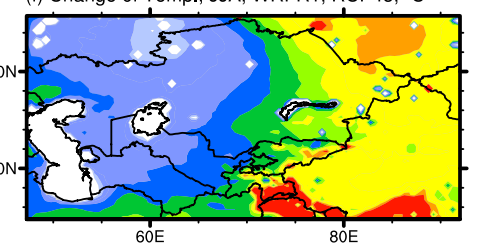

(i) Change of Temp., JJA, WRFR2, RCP45, ${ }^{\circ} \mathrm{C}$

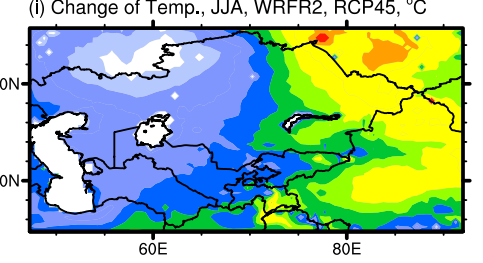

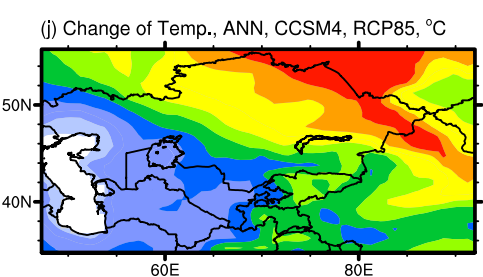

(m) Change of Temp., ANN, WRFR1, RCP85, ${ }^{\circ} \mathrm{C}$

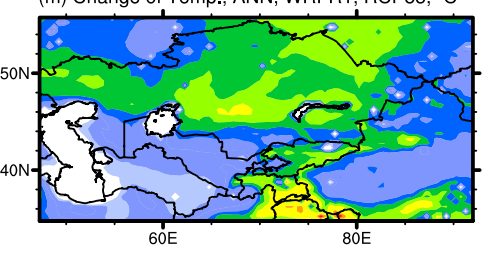

(p) Change of Temp., ANN, WRFR2, RCP $85,{ }^{\circ} \mathrm{C}$

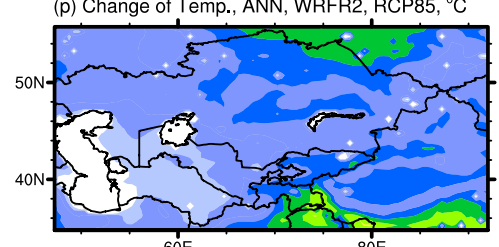

(k) Change of Temp., DJF, CCSM4, RCP85, ${ }^{\circ} \mathrm{C}$

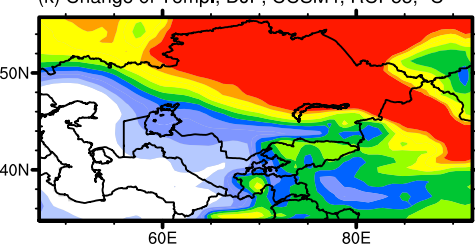

(n) Change of Temp., DJF, WRFR1, RCP85, ${ }^{\circ} \mathrm{C}$

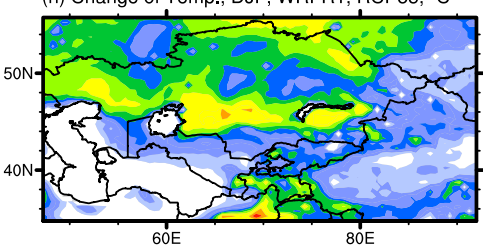

(q) Change of Temp., DJF, WRFR2, RCP $85,{ }^{\circ} \mathrm{C}$

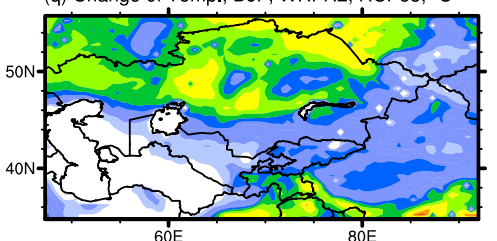

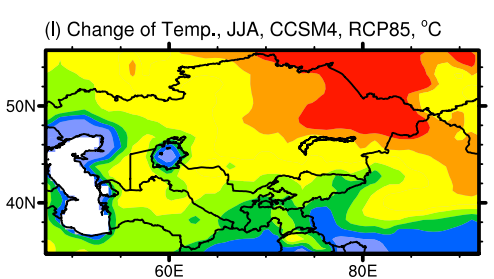

(0) Change of Temp., JJA, WRFR1, RCP85, ${ }^{\circ} \mathrm{C}$

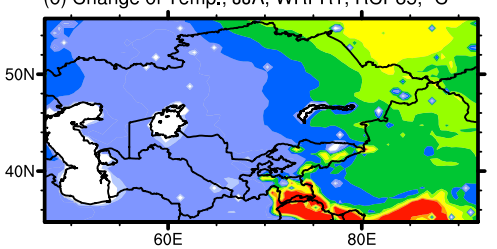

(r) Change of Temp., JJA, WRFR2, RCP85, ${ }^{\circ} \mathrm{C}$

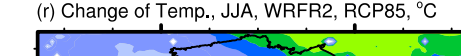

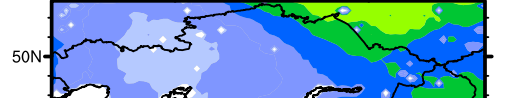
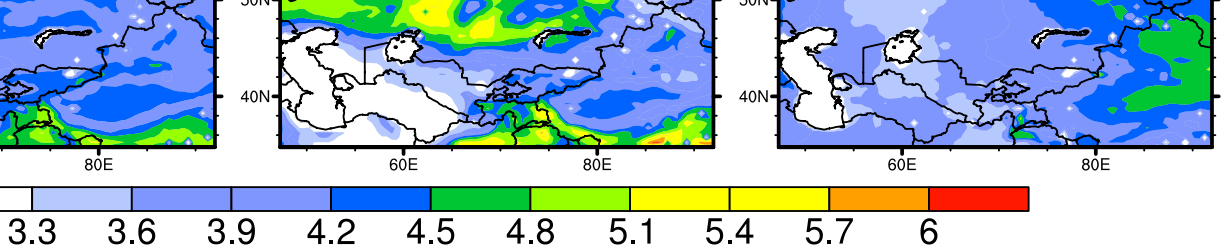

3.9
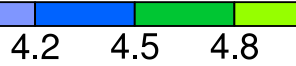

5.1

Fig. 10 Future changes of mean temperature in ANN (1st column), DJF (2nd column) and JJA (3rd column) during 2071-2100 derived from the CCSM4, WRFR1 and WRFR2 under RCP4.5 and RCP8.5 scenario, base year: $1986-2005$, unit: ${ }^{\circ} \mathrm{C}$. All pass the significance at the $95 \%$ confidence level using the two-tailed Student's $t$ test 
precipitation-related indices. Furthermore, the LSMs used in the dynamic downscaling experiment do not impact the simulation of climate indices significantly. Nonetheless, the Noah-MP scheme generally outperforms the Noah scheme in the simulation of average climate states in the CA.

\section{Future projections}

All projected changes represent the difference between the means of the future (2071-2100) and the past (1986-2005) periods.

\subsection{Temperature and temperature-related indices}

Figure 10 illustrates the projected changes in mean ANN, DJF, and JJA temperatures during 2071-2100 relative to the base year (1986-2005). Overall, both CCSM4 and WRFR2 project a significant increase in the mean temperature. The rising temperature are significantly more pronounced in the higher latitudes and high-altitude regions. Under the RCP4.5 scenario, the CCSM4 model projects that mean ANN temperature will increase by a maximum of $3{ }^{\circ} \mathrm{C}$ in northeastern CA (Fig. 10a), and under the RCP8.5 scenario, the maximum increase in mean ANN temperature will also occur in the northeastern CA and can exceed $6{ }^{\circ} \mathrm{C}$ (Fig. 10j). Conversely, the WRFR2 experiment indicates that the temperature rises of the CA will mainly occur in the middle and high latitudes and the Tibetan Plateau. The rises in temperature projected by the WRFR2 experiment are less than those of the CCSM4 model (Fig. 10d, m). The projection of the CCSM4 model shows that DJF temperatures will also rise significantly in the future, and areas with high temperature rises will cover large stretches of the CA such as the eastern-central Kazakhstan and northwestern Xinjiang. Based on the CCSM4 results, the DJF temperature of the CA will rise by a maximum of greater than $3{ }^{\circ} \mathrm{C}$ and $6{ }^{\circ} \mathrm{C}$ under the RCP4.5 and RCP 8.5 scenarios, respectively (Fig. 10b, k). The projections of WRFR1 and WRFR2 experiment are consist, with lower temperature rises compared to the CCSM4 model. According to the dynamic downscaling, the DJF temperature of the CA will rise by a maximum of $2.5^{\circ} \mathrm{C}$ and $5{ }^{\circ} \mathrm{C}$ under the RCP4.5 and RCP8.5 scenarios, respectively (Fig. 10e, h, n, q). For JJA temperatures, there are significant differences between the results of the CCSM4 model and dynamic downscaling experiments. The projection by CCSM 4 shows that the areas with high temperature rises will be located in the eastern Kazakhstan and the maximum temperature rise will be $3{ }^{\circ} \mathrm{C}$ and $6{ }^{\circ} \mathrm{C}$ under the RCP4.5 and RCP 8.5 scenarios, respectively (Fig. 10c, 1). The areas with high temperature rise in the WRFR1 and WRFR2 are smaller than that of the CCSM4 model. Figure 11a shows that the change in the temperature of the CA will be mostly increasing, with the rises in temperature larger in the RCP8.5 scenario. The overall trends of temperature in the CA projected by the dynamic downscaling experiments are consist with CCSM4 model under different greenhouse gas emission scenarios. Under the RCP4.5 scenario, the CCSM4 model and WRFR2 experiment both project that ANN, DJF, March-April-May (MAM), JJA and September-October-November (SON) temperatures will increase by the rates of $0.21{ }^{\circ} \mathrm{C} /$ decade, $0.22{ }^{\circ} \mathrm{C} /$ decade, $0.21{ }^{\circ} \mathrm{C} /$ decade, $0.21{ }^{\circ} \mathrm{C} /$ decade and $0.16^{\circ} \mathrm{C} /$ decade, respectively. However, the CCSM4 and WRFR1, WRFR2 projections differ under the RCP8.5 scenario, with the CCSM4 model projecting a larger rise in ANN temperature than WRFR1 and WRFR2 experiments. Under the RCP8.5 scenario, the CCSM4 model projects that the ANN, DJF, MAM, JJA, and SON temperatures of the CA will rise by the rate of $0.59{ }^{\circ} \mathrm{C} /$ decade, $0.64{ }^{\circ} \mathrm{C} /$ decade, $0.59{ }^{\circ} \mathrm{C} /$ decade, $0.64{ }^{\circ} \mathrm{C} /$ decade and $0.51{ }^{\circ} \mathrm{C} /$ decade, respectively. However, the WRFR1 and WRFR2 experiments project that the ANN, DJF, MAM, JJA, and SON temperatures of the CA will rise at a rate of $0.51{ }^{\circ} \mathrm{C} / \mathrm{dec}$ ade, $0.59^{\circ} \mathrm{C} / \mathrm{dec}$ de, $0.59{ }^{\circ} \mathrm{C} /$ decade, $0.59{ }^{\circ} \mathrm{C} / \mathrm{dec}$ ade and $0.43{ }^{\circ} \mathrm{C} /$ decade, respectively (Fig. 11b).

Figure 12 illustrates that all the temperature-related indices have been projected to increase significantly except FD, and FD is projected to decrease significantly. This shows that the minimum temperature of the $\mathrm{CA}$ is increasing, and the number of days with minimum temperatures lower than $0{ }^{\circ} \mathrm{C}$ are decreasing. This is consistent with the significant rises in temperature projected. The projection by the CCSM4 model shows that SU will increase more significantly in the higher latitudes than the lower latitudes and high-altitude regions. The projection also shows that the maximum increase in $\mathrm{SU}$ will be greater than 30 days and 50 days under the RCP4.5 and RCP8.5 scenarios, respectively (Fig. 12a, e). The projection by the dynamic downscaling experiments show that the maximum increase in SU will be 25 days under the RCP4.5 scenario and 50 days under the RCP8.5 scenario, and the areas where large increases in SU occur are much smaller in the WRFR1 and WRFR2 results than the CCSM4 results (Fig. 12i, m, q, u). With regards to the TXX index, the CCSM4 model projects that the increase in TXX will be more pronounced in the northeastern CA than in the southwestern CA under the RCP4.5 scenario, with the maximum increase in TXX being $3.5^{\circ} \mathrm{C}$ (Fig. 12b). Under the RCP8.5 scenario, the maximum increase in TXX is expected to exceed $6{ }^{\circ} \mathrm{C}$, and most of the areas will show large increases in TXX (Fig. 12f). Furthermore, the WRFR1 and WRFR2 projected smaller increases in TXX than the CCSM4 model, with the maximum increase in TXX of $2.5{ }^{\circ} \mathrm{C}$ under the 


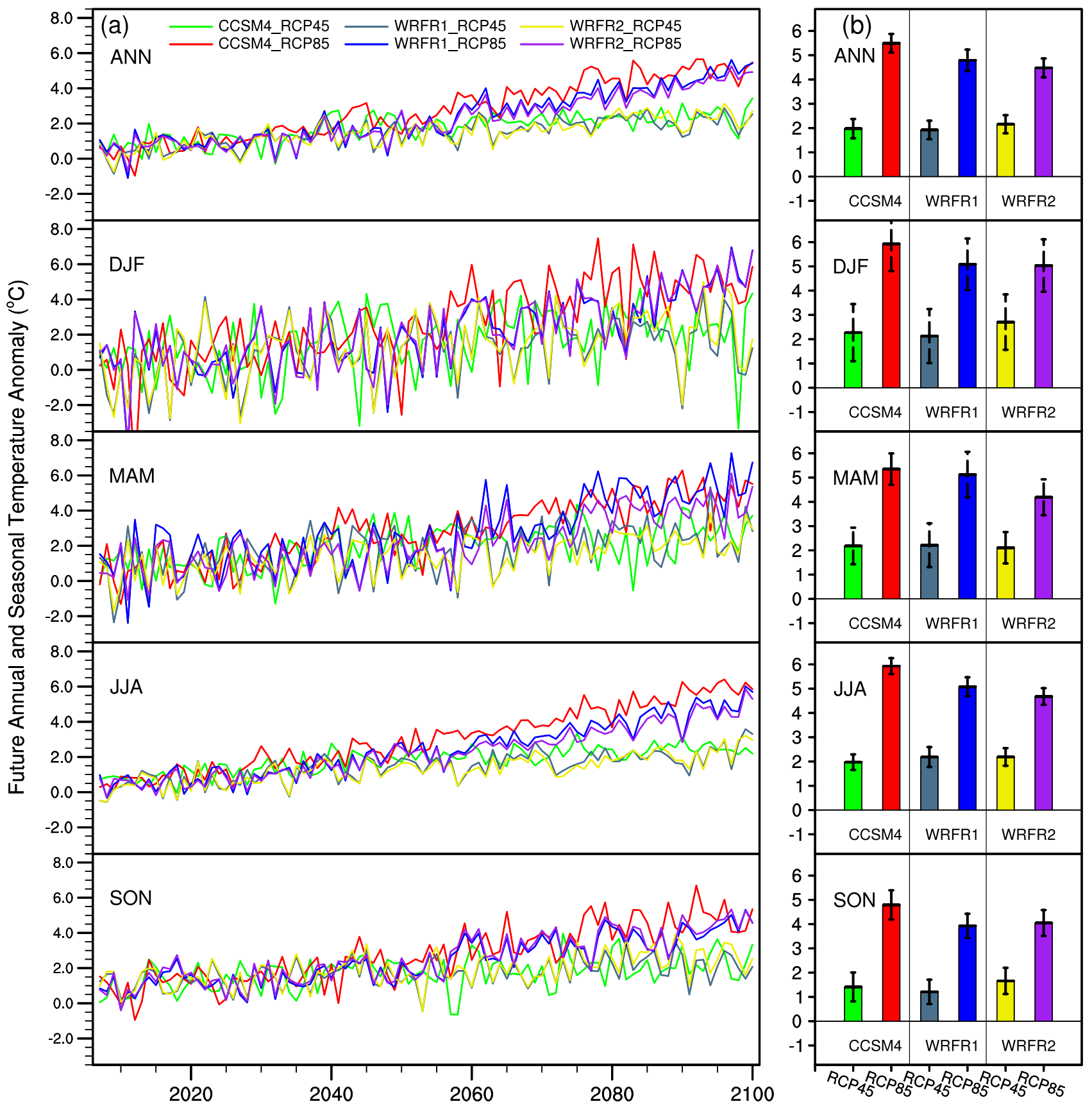

Fig. 11 Time series of temperature anomalies (a) and changes in annual and seasonal mean temperature (b) during 2007-2100 over the CA derived from CCSM4, WRFR1 and WRFR2 under RCP4.5 and

RCP4.5 scenario (Fig. $12 \mathrm{j}, \mathrm{r}$ ) and $5{ }^{\circ} \mathrm{C}$ under the RCP8.5 scenario (Fig. 12n, v). Under the RCP4.5 scenario, the CCSM4 model projects that FD will decrease in most parts of the CA, and the areas of the CA where large decreases in FD occur may see FD decrease by 30 days (Fig. 12c). Under the RCP8.5 scenario, the CCSM4 model projected even greater decreases in FD, where FD will decrease by more than 50 days in most parts of the CA (Fig. $12 \mathrm{~g}$ ). The
RCP8.5 scenario, base year: 1986-2005, unit: ${ }^{\circ} \mathrm{C}$. The error bars indicate the $95 \%$ confidence intervals

projection by the dynamic downscaling experiments also show that FD will decrease over the CA, with the lower latitudes and high-altitude regions seeing larger decreases in FD than the higher latitudes. However, the WRFR1 and WRFR2 experiment generally projected smaller decreases in FD than the CCSM4 model; the dynamic downscaling experiments projected that FD will decrease by approximately 25 days and 45-50 days under the RCP4.5 and RCP8.5 scenarios, 


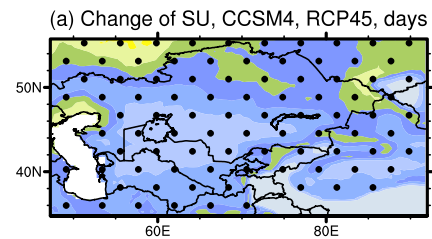

(e) Change of SU, CCSM4, RCP85, days

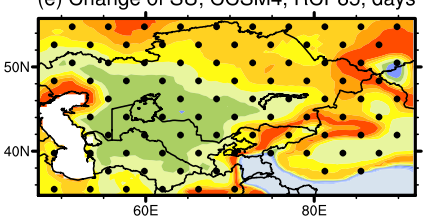

(i) Change of SU, WRFR1, RCP45, days

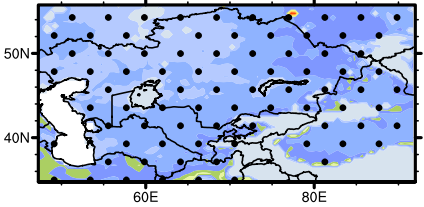

(m) Change of SU, WRFR1, RCP85, days

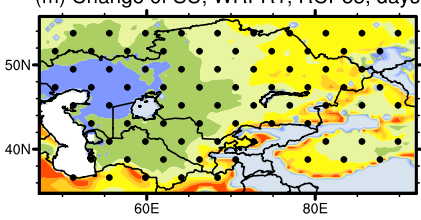

(q) Change of SU, WRFR2, RCP45, days

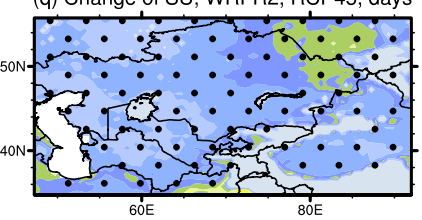

(u) Change of SU, WRFR2, RCP85, days

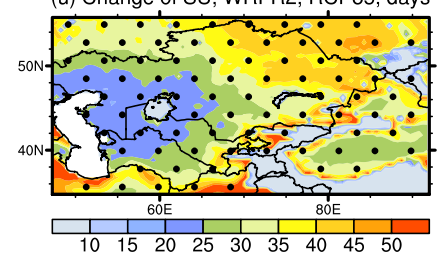

Fig. 12 Future change of temperature-related extreme indices of SU (1st column, unit: days), TXX (2nd column, unit: $\left.{ }^{\circ} \mathrm{C}\right)$, FD (3rd column, unit: days) and TNN (4th column, unit: ${ }^{\circ} \mathrm{C}$ ) during 2071-2100 derived from the CCSM4, WRFR1 and WRFR2 under RCP4.5 and

respectively (Fig. 12k, o, s, w). For most part of the CA. The CCSM4 model and dynamic downscaling experiments both predict that TNN will increase significantly, and the increase in TNN grows with increasing latitude. The CCSM4 model projects that TNN will increase by $5-6{ }^{\circ} \mathrm{C}$ under the RCP4.5 scenario (Fig. 12d) and TXX will increase by more than $10{ }^{\circ} \mathrm{C}$ in the northern $\mathrm{CA}$ and the northeastern Xinjiang under the RCP8.5 scenario (Fig. 12h). The projections of the WRFR2 experiment under RCP4.5 are essentially the same as those of the CCSM4 model, but under the RCP8.5 scenario, the area where TNN is expected to increase

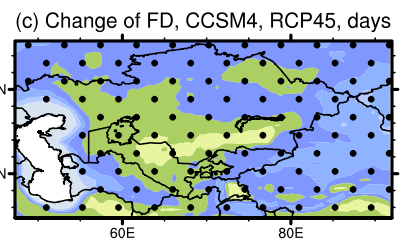

(g) Change of FD, CCSM4, RCP85, days

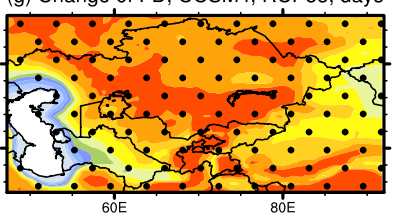

(k) Change of FD, WRFR1, RCP45, days

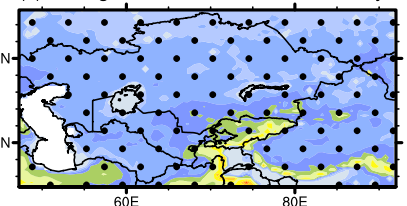

(o) Change of FD, WRFR1, RCP85, days
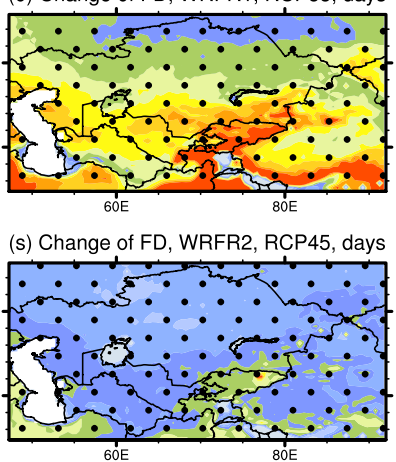

(w) Change of FD, WRFR2, RCP85, days
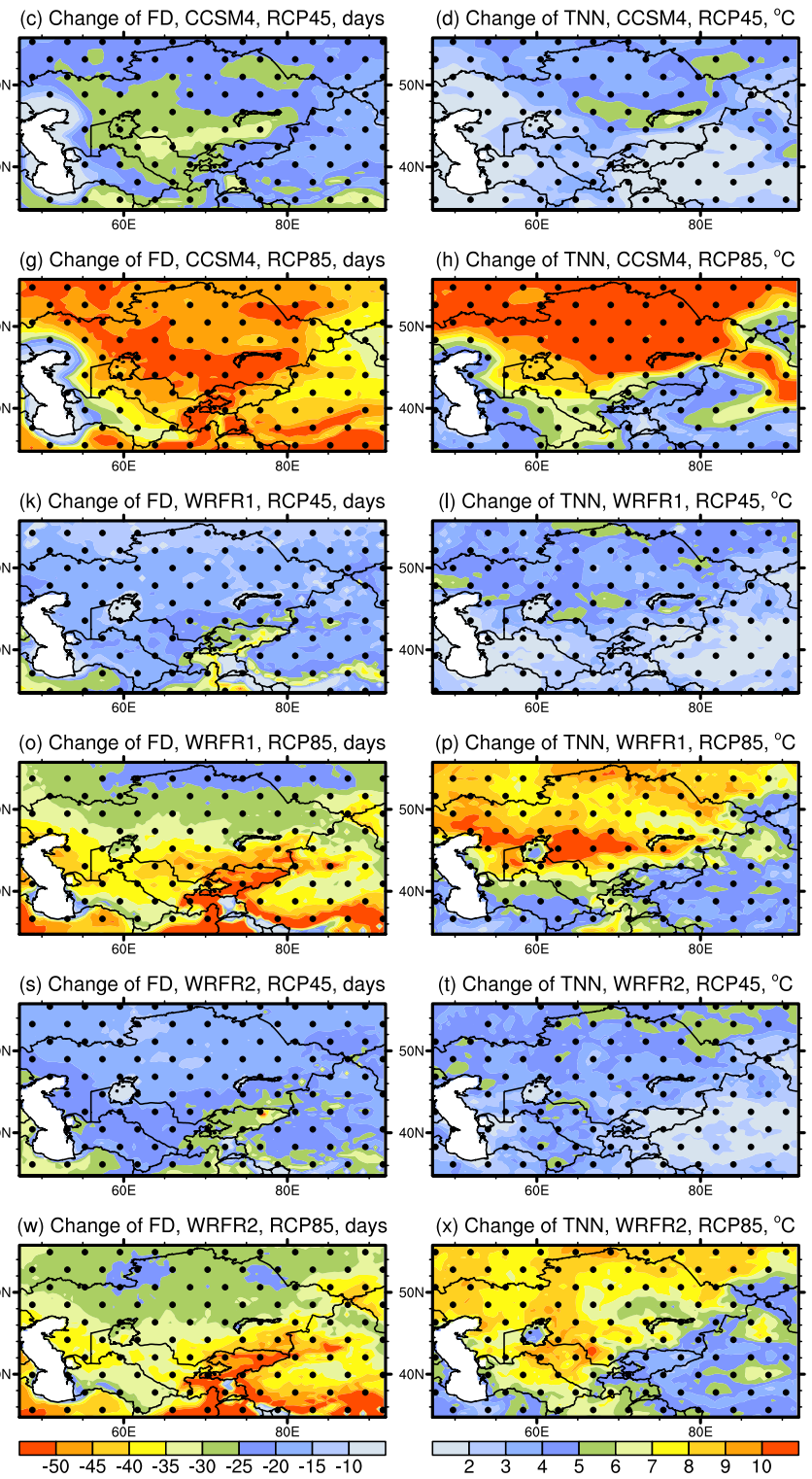

(h) Change of TNN, CCSM $4, \mathrm{RCP} 85,{ }^{\circ} \mathrm{C}$

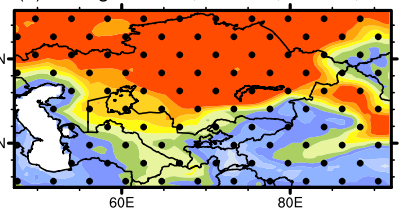

(I) Change of TNN, WRFR $1, \mathrm{RCP} 45,{ }^{\circ} \mathrm{C}$

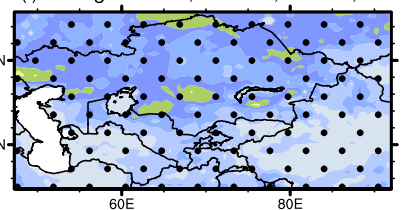

(p) Change of TNN, WRFR1, RCP85, ${ }^{\circ} \mathrm{C}$

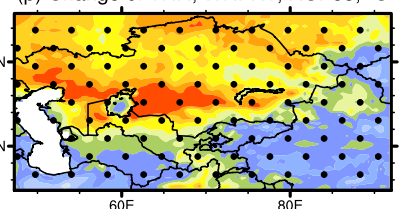

(t) Change of TNN, WRFR2, RCP45, ${ }^{\circ} \mathrm{C}$

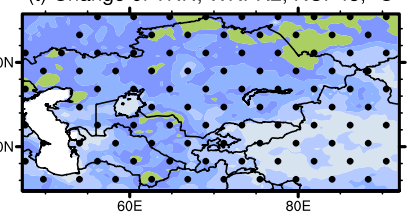

(x) Change of TNN, WRFR2, RCP $85,{ }^{\circ} \mathrm{C}$

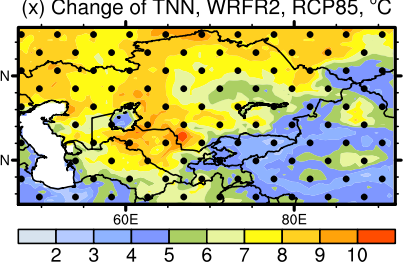

RCP8.5 scenario related to the base year: 1986-2005. The dotted regions indicate significance at the $95 \%$ confidence level using the two-tailed Student's t test

significantly is smaller in the WRFR1 and WRFR2 results (Fig. 121, p, t, x).

Figure 13a shows that the temporal trends of the temperature-related indices are generally consistent with their spatial patterns of trend, with SU, TXX, and TNN projected to increase significantly, while FD is expected to decrease. Furthermore, the trends projected by the CCSM4 model and dynamic downscaling experiments are largely consistent with each other, and both of these simulations show that different greenhouse gas emission scenarios lead to significant differences in the temperature-related indices. 
(a)

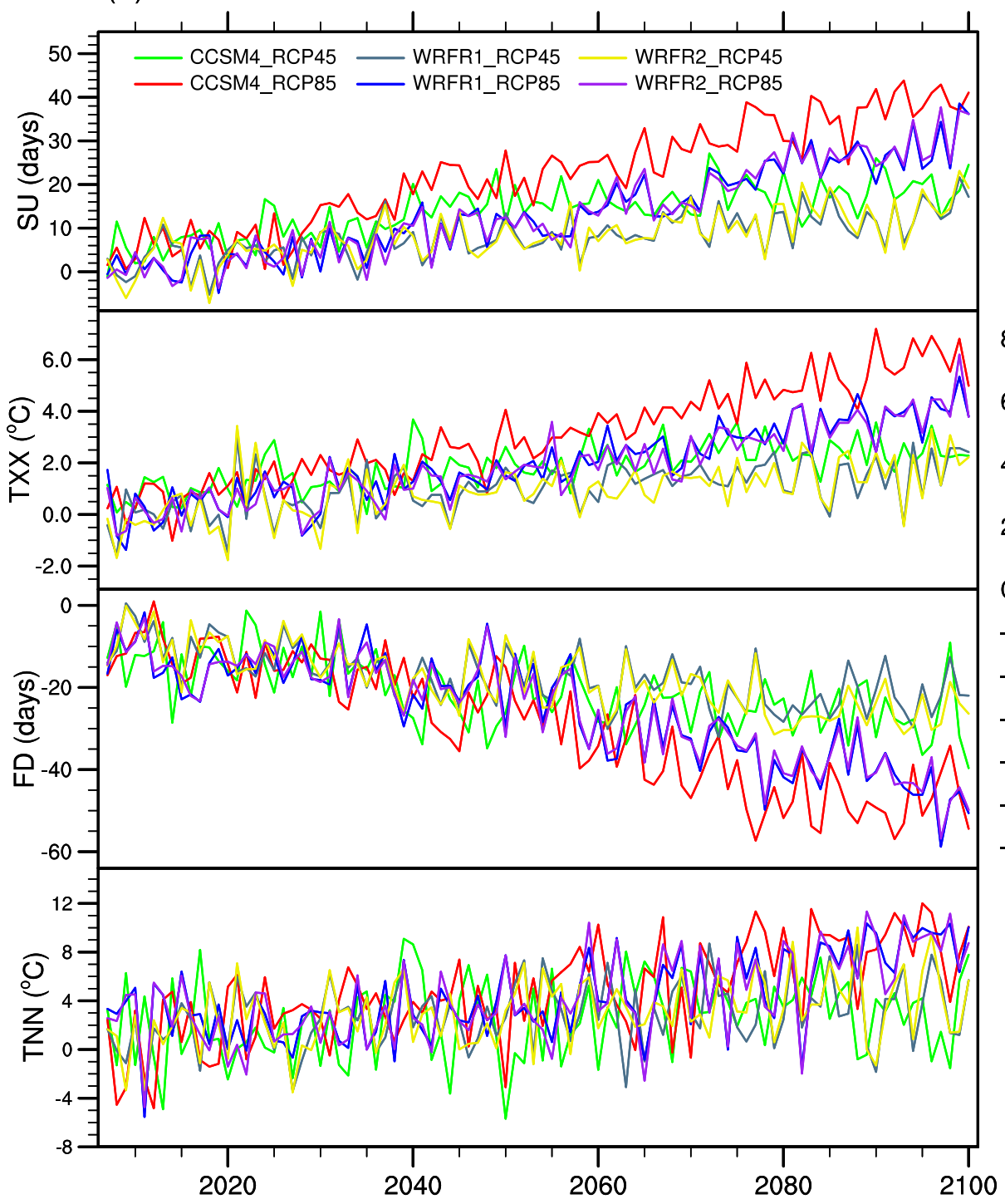

(b)

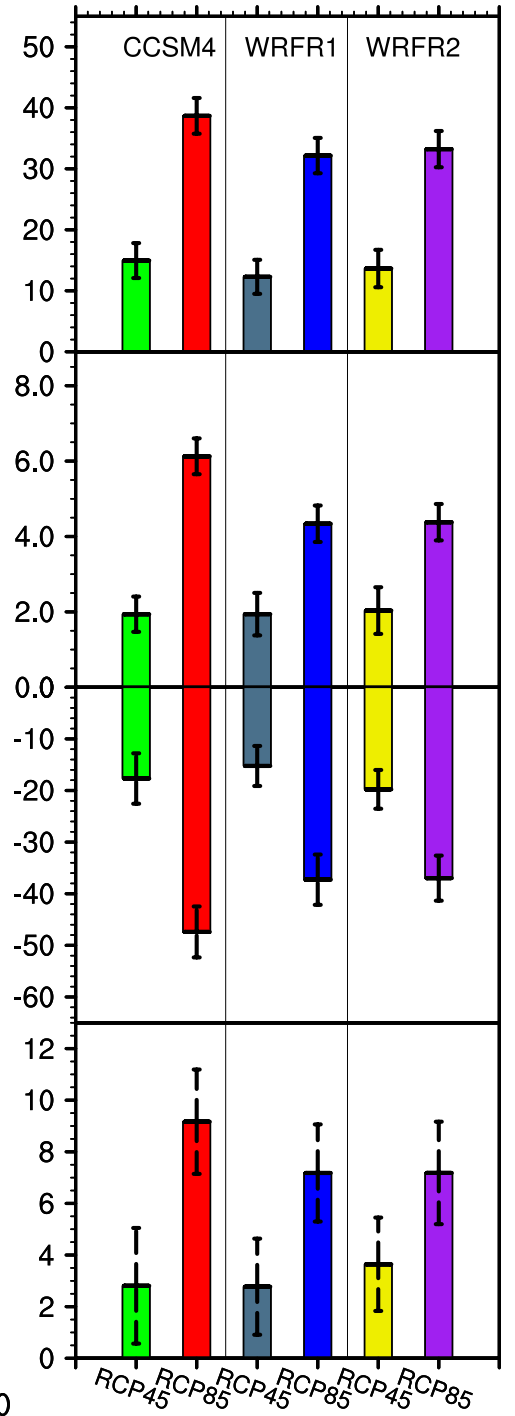

Fig. 13 a Time series of temperature-related extreme indices of SU, TNN, FD, TNN and their changes during 2007-2100 (b) over the CA derived from CCSM4, WRF1 and WRFR2 under RCP4.5 and

Figure 13b shows that the CCSM4 model and WRFR1, WRFR2 experiments projected similar trends in the temperature-related indices from 2007 to 2100, and the models only differ slightly in the magnitude of the changes. Under the RCP4.5 scenario, the CCSM4 model and WRFR1 and WRFR2 experiments project that SU will increase by 15 days/94 years; under the RCP8.5 scenario, the projections of CCSM4 and WRFR1, WRFR2 are 40 days/94 years and 35 days/94 years, 35 days/94 years. Under the RCP4.5 scenario, the CCSM4 and dynamic downscaling results both show that TXX will increase by $2.0^{\circ} \mathrm{C}$ over the next 94 years. Under the RCP8.5 scenario, CCSM4 predicts an increase of $6.0^{\circ} \mathrm{C}$, whereas WRFR2 predicts an increase
RCP8.5 scenario, base year: 1986-2005. The error bars indicate the 95\% confidence intervals

of $4.2{ }^{\circ} \mathrm{C}$. With regards to the changes in FD over the next 94 years, CCSM4 and dynamic downscaling results all project that FD will decrease by approximately 16 days under the RCP4.5 scenario. Under the RCP8.5 scenario, the CCSM4 and WRFR-projected decreases in FD of 48 days and 40 days, respectively. The CCSM4 and WRFR results both show that the TNN of the CA will increase by $3{ }^{\circ} \mathrm{C}$ under the RCP4.5 scenario, while under the RCP8.5 scenario, the CCSM4 results show that TNN will increase by $9{ }^{\circ} \mathrm{C}$. The WRFR 1 and WRFR 2 results show that TNN will increase by approximately $7{ }^{\circ} \mathrm{C}$.

The projections by the CCSM4 model and dynamic downscaling experiments all show that the temperature will 


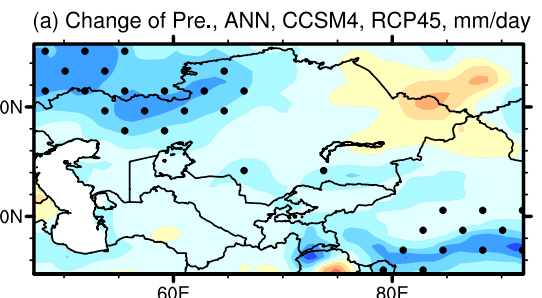

(d) Change of Pre., ANN, WRFR1, RCP45, mm/day

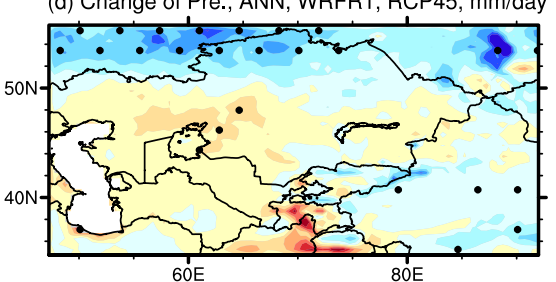

(g) Change of Pre., ANN, WRFR2, RCP45, mm/day

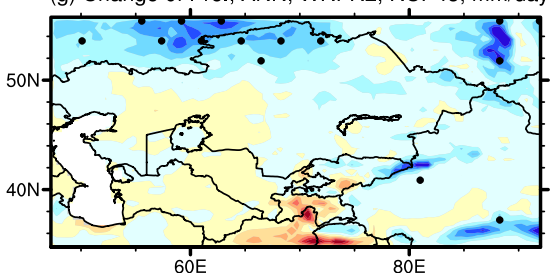

(j) Change of Pre., ANN, CCSM4, RCP85, mm/day

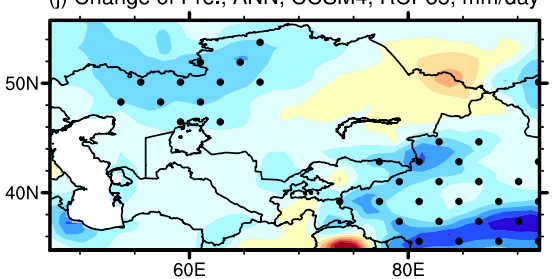

(m) Change of Pre., ANN, WRFR1, RCP85, mm/day

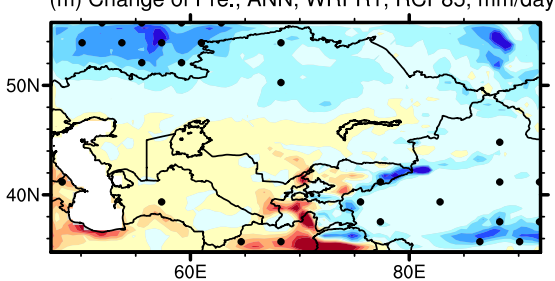

(p) Change of Pre., ANN, WRFR2, RCP85, mm/day

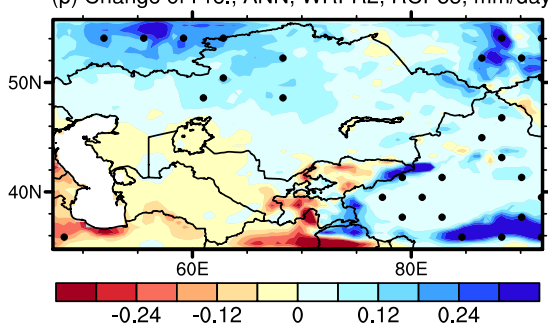

(b) Change of Pre., DJF, CCSM4, RCP45, mm/day

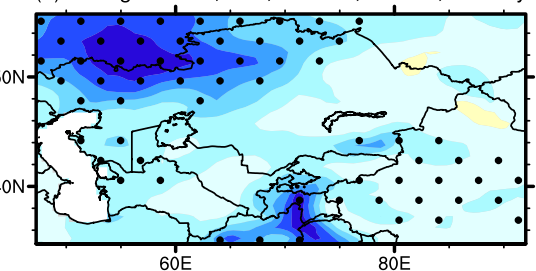

(e) Change of Pre., DJF, WRFR1, RCP45, mm/day

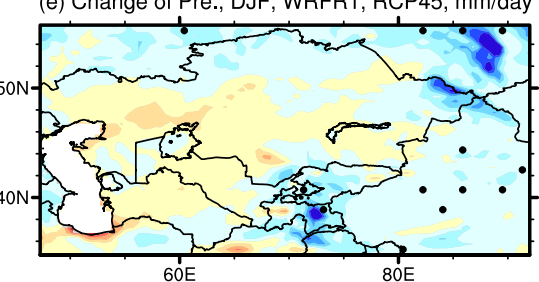

(h) Change of Pre., DJF, WRFR2, RCP45, mm/day

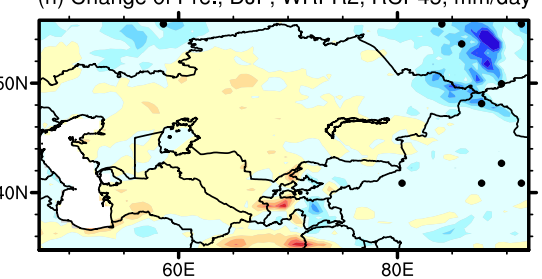

(k) Change of Pre., DJF, CCSM4, RCP85, mm/day

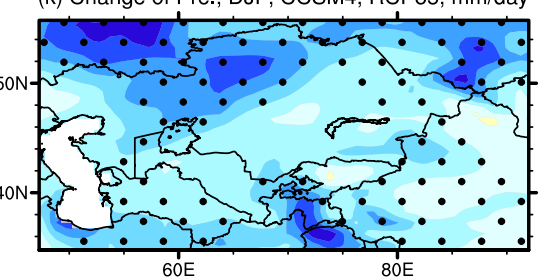

(n) Change of Pre., DJF, WRFR1, RCP85, mm/day

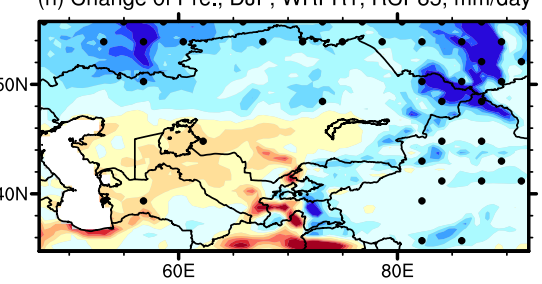

(q) Change of Pre., DJF, WRFR2, RCP85, mm/day

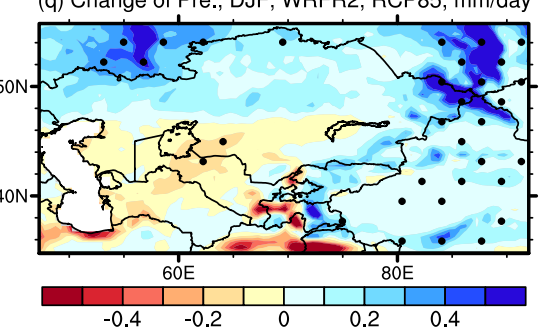

(c) Change of Pre., JJA, CCSM4, RCP45, mm/day

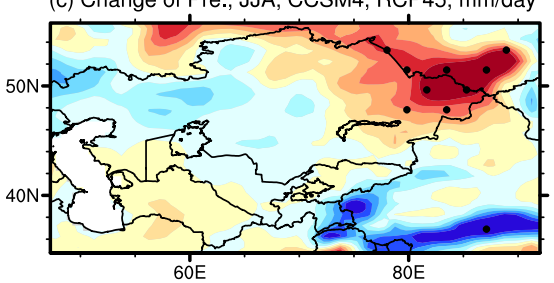

(f) Change of Pre., JJA, WRFR1, RCP45, mm/day

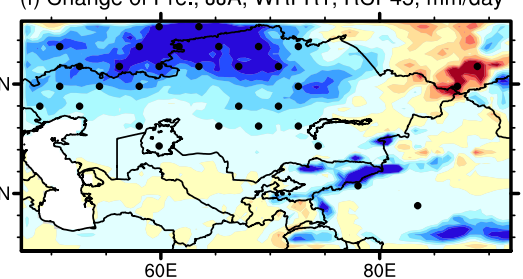

(i) Change of Pre., JJA, WRFR2, RCP45, mm/day

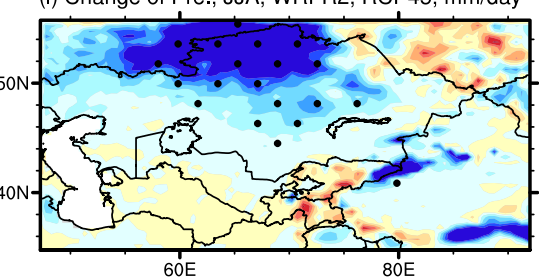

(I) Change of Pre., JJA, CCSM4, RCP85, mm/day

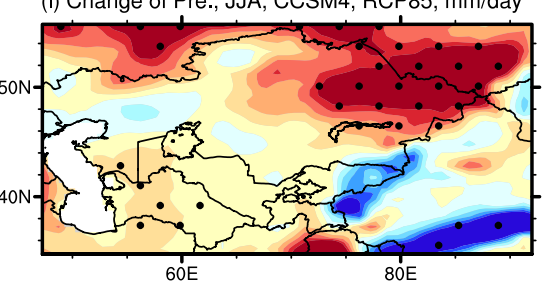

(o) Change of Pre., JJA, WRFR1, RCP85, mm/day

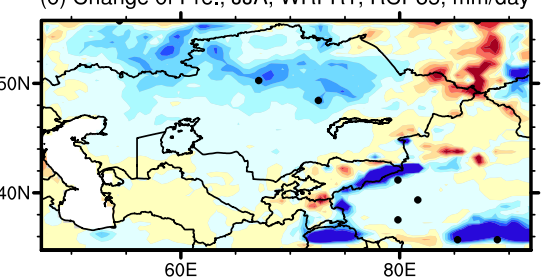

(r) Change of Pre., JJA, WRFR2, RCP85, mm/day

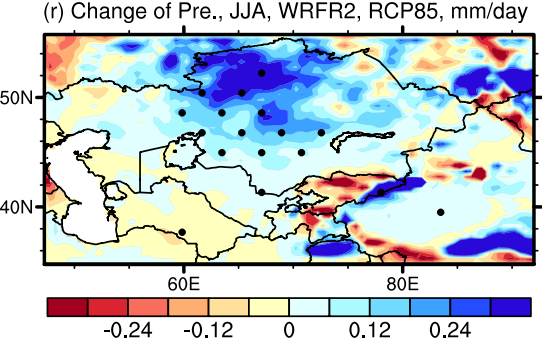

Fig. 14 Similar to Fig. 10, but for precipitation, unit: mm/day. The dotted regions indicate significance at the $95 \%$ confidence level using the two-tailed Student's t test

rise significantly. Furthermore, the greater the emission of GHG, the more significant the rises in temperature. These temperature rises will be most pronounced in DJF and least pronounced in SON. Over the next few decades, the ANN temperature of the $\mathrm{CA}$ is projected to rise by $2.0^{\circ} \mathrm{C}$ and $5.0^{\circ} \mathrm{C}$ under the RCP4.5 and RCP8.5 scenarios, respectively.
Therefore, the suppression of greenhouse gas emissions is crucial for restricting the temperature increase in the CA. The temperature rises projected by the CCSM4 model are generally larger than that projected by the WRFR 1 and WRFR2 experiment. Therefore, through dynamic downscaling, the bias produced by the simulation of CCSM4 model 
could be reduced. This maybe come from the different GHG increases in the WRF and CCSM4 model. The projected temperature-related indices of the CA show that extreme temperatures will increase, and the number of low-temperature days will decrease. Furthermore, the increase in minimum temperature is greater than the increase in maximum temperature. The changes in the temperature-related indices of the CA were significantly affected by the greenhouse gas emission scenarios, with the increase in extreme temperatures and decrease in low-temperature days in the RCP8.5 scenario twice that of the RCP4.5 scenario. Therefore, the reduction of greenhouse gas emissions is of utmost importance for controlling extreme temperatures in the CA.

\subsection{Precipitation and precipitation-related indices}

Under RCP4.5, the ANN daily mean precipitation of the CA is projected to increase in the future in the CCSM4 model. This increase mainly occurs in two high-value regions located in the Tibetan Plateau and northwestern CA, where
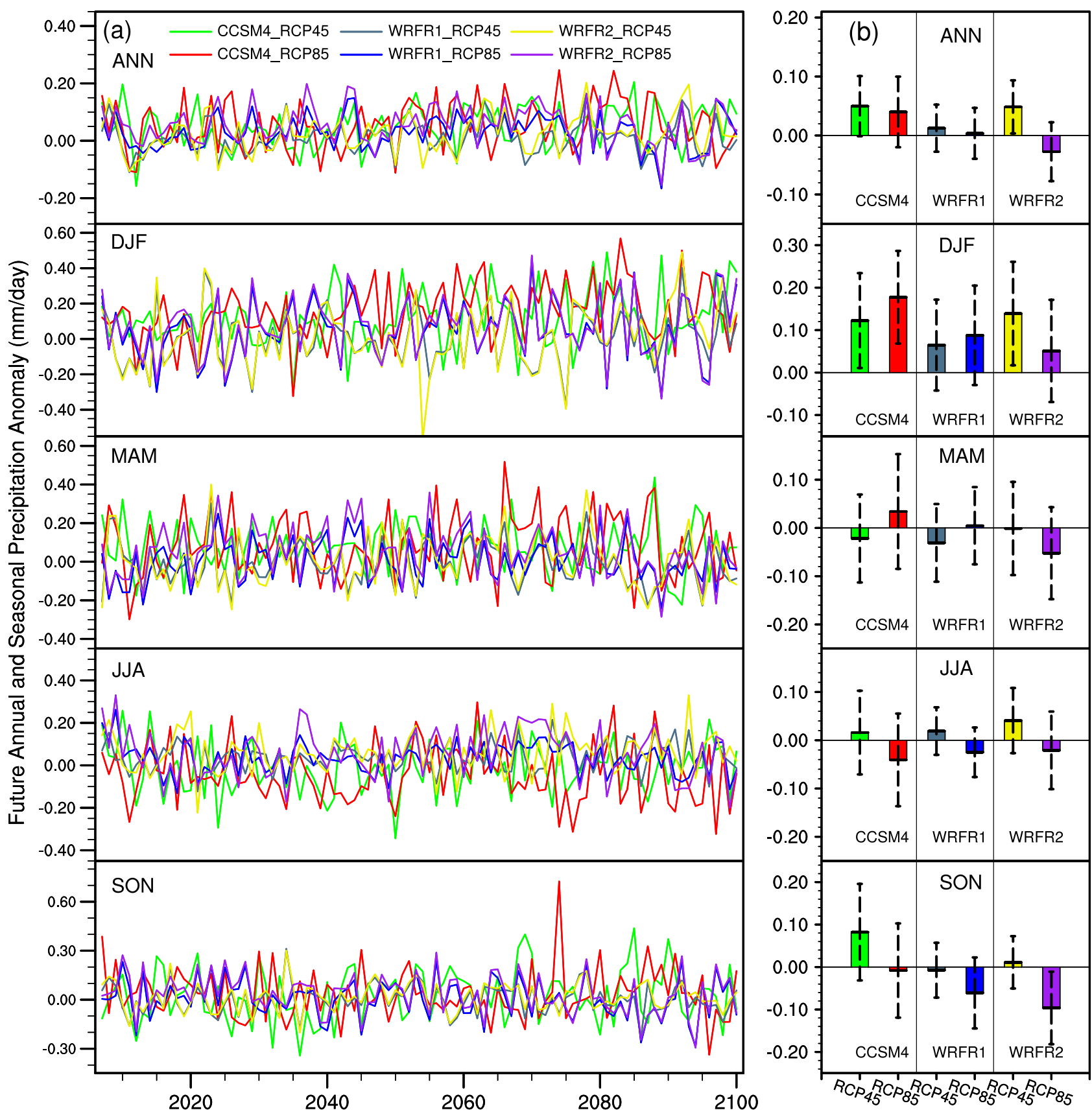

Fig. 15 Similar to Fig. 11, but for precipitation, unit: $\mathrm{mm} /$ day 
the maximum increase in precipitation is projected to be $0.2 \mathrm{~mm}$. An insignificant decrease in precipitation will occur in the northeastern $\mathrm{CA}$, with a projected maximum decrease of $-0.15 \mathrm{~mm}$ (Fig. 14a). Under RCP8.5, the change in precipitation over the $\mathrm{CA}$ is projected to be greater than that under the RCP4.5 scenario, with the exception of a slight increase of $0.25 \mathrm{~mm}$ in the Tibetan Plateau (Fig. 14j). The projections of the WRFR1 and WRFR2 experiments indicate that the ANN precipitation of the CA will mainly increase in high-latitude and high-altitude regions and decrease in the southwestern CA (Fig. 14d, j, m, p). The CCSM4 model projects that there will be a significant increase of greater than $0.4 \mathrm{~mm}$ for the DJF precipitation, and the projections under the RCP4.5 and RCP8.5 scenarios from CCSM4 are consistent with each other, except for the larger increased precipitation area in the RCP8.5 scenario (Fig. 14b, k). The dynamic downscaling projections under RCP4.5 indicate that the DJF precipitation of will increase in the northerncentral CA but decrease in the southwestern CA, and DJF precipitation will increase significantly north of $50^{\circ} \mathrm{N}$ and Xinjiang, but decrease significantly in the southwestern CA (Fig. 14e, h, n, q). Under the RCP4.5 scenario, the projections of the CCSM4 for JJA precipitation show an increase center in the northeastern CA and a decrease center in the northern Tibetan Plateau (Fig. 14c). Under the RCP8.5 scenario, most regions of the CA will show significant decreases in JJA precipitation (Fig. 141). The dynamic downscaling projections for JJA precipitation significantly differ
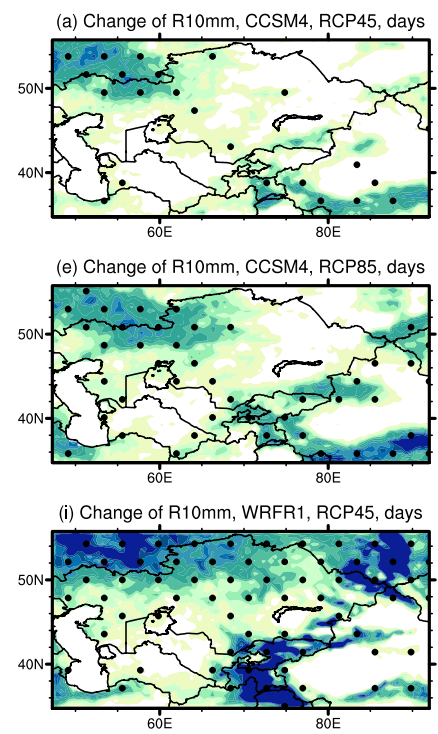

(m) Change of R10mm, WRFR1, RCP85, days

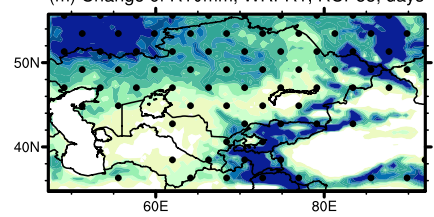

(q) Change of R10mm, WRFR2, RCP45, days

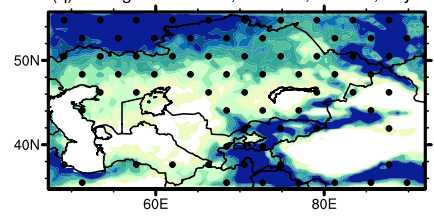

(u) Change of R10mm, WRFR2, RCP85, days

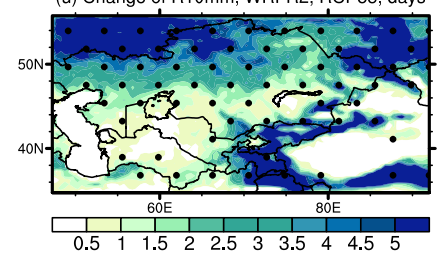

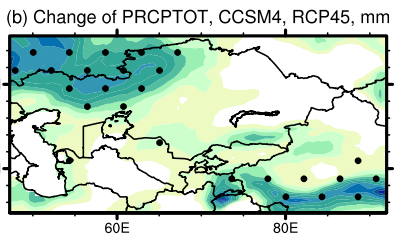

(f) Change of PRCPTOT, CCSM4, RCP85, mm

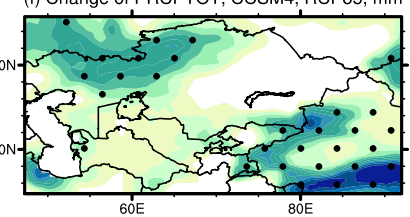

(j) Change of PRCPTOT, WRFR1, RCP45, mm

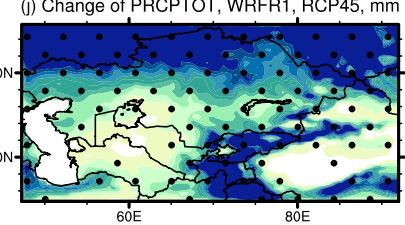

(n) Change of PRCPTOT, WRFR1, RCP85, mm

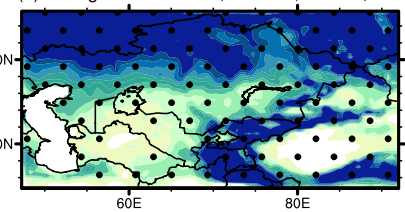

(r) Change of PRCPTOT, WRFR2, RCP45, mm

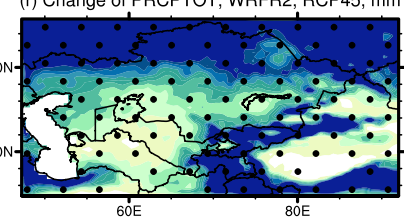

(v) Change of PRCPTOT, WRFR2, RCP85, mm

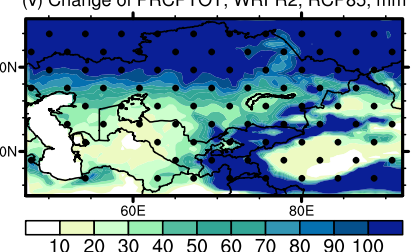

Fig. 16 Similar to Fig. 14, but for precipitation-related extreme indices of R10mm (1st column, unit: days), PRCPTOT (2nd column, unit: $\mathrm{mm}$ ), SDII (3rd column, unit: mm/day), and CDD (4th column,
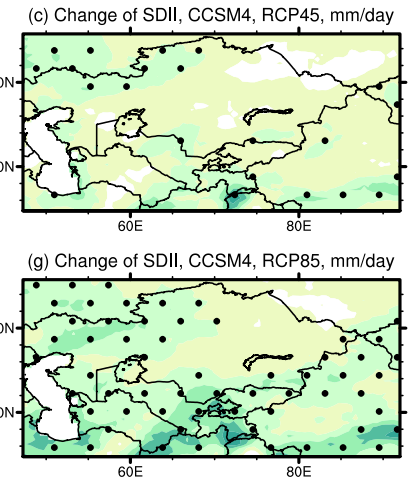

(k) Change of SDII, WRFR1, RCP45, mm/day
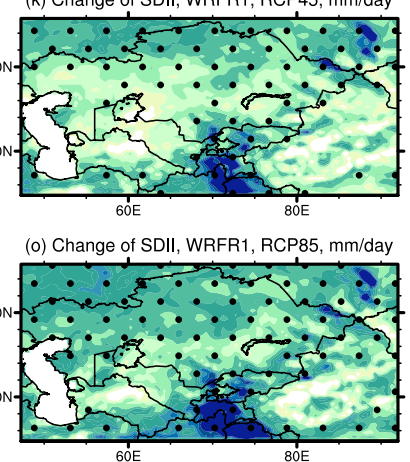

(s) Change of SDII, WRFR2, RCP45, $\mathrm{mm} / \mathrm{day}$
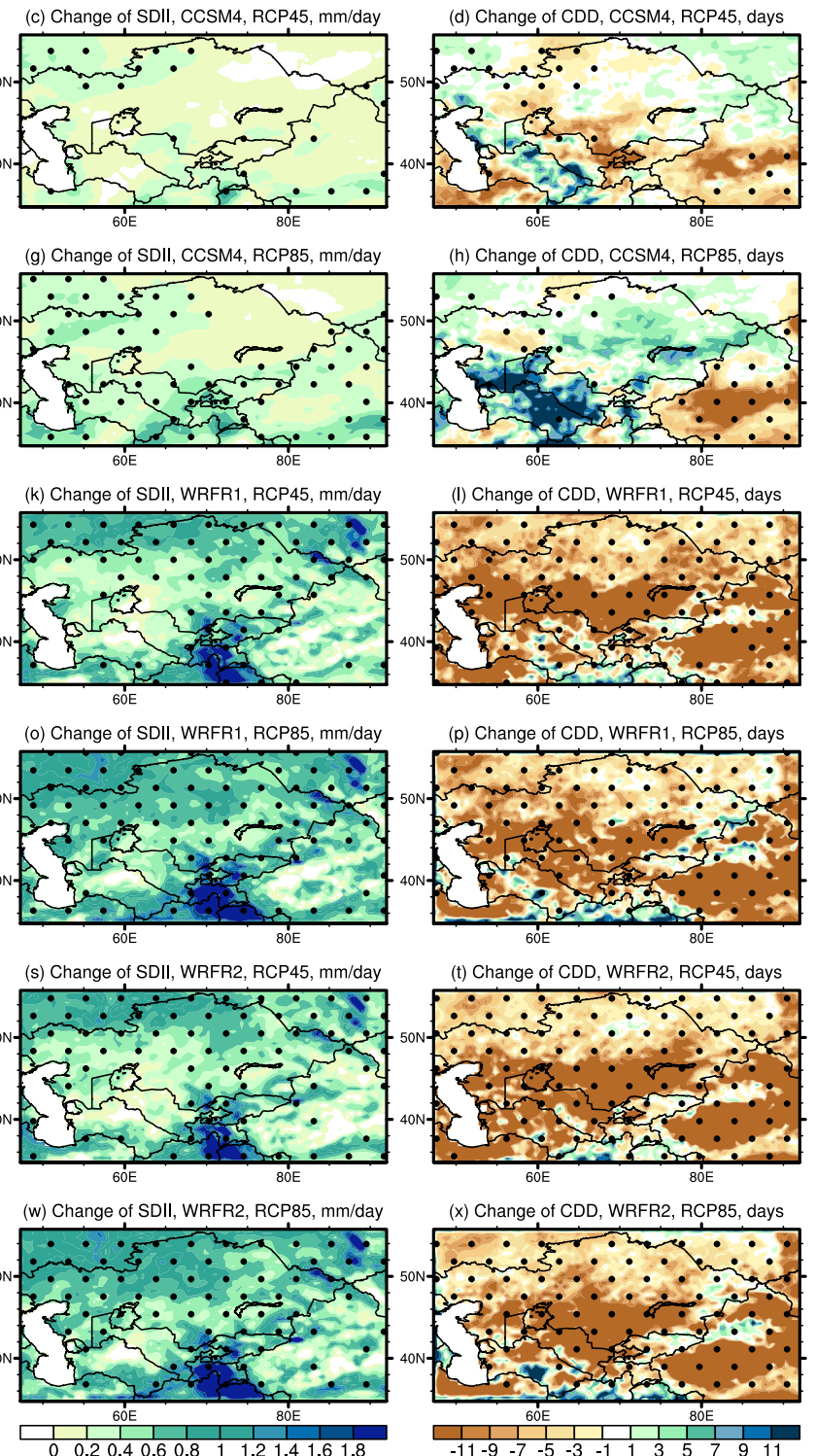

(p) Change of CDD, WRFR1, RCP85, days
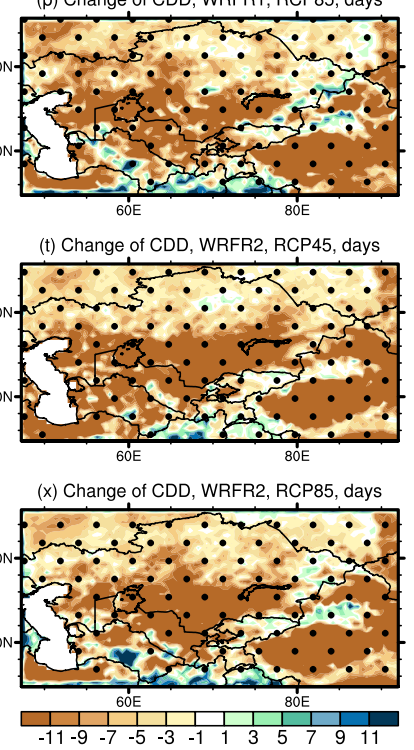

unit: days). The dotted regions indicate significance at the $95 \%$ confidence level using the two-tailed Student's t test 
from those of the CCSM4 model, because the RCP4.5 and RCP8.5 projections of the WRFR2 experiment both indicate that JJA precipitation will increase in the northwestern CA and the Tibetan Plateau, but decrease in the southwestern and northeastern CA (Fig. 14f, i, o, r). Figure 15 illustrates the projected temporal evolution of annual and seasonal mean daily precipitations. Overall, the change in the precipitation of the CA will be insignificant, and the differences between the CCSM4 and WRFR2 results also appear to be insignificant (Fig. 15a). Furthermore, the precipitation of the CA will change similarly under the RCP4.5 and RCP8.5 scenarios. Based on a quantitative analysis of the annual and seasonal precipitation trends of the CA (Fig. 15b), it is found that the projections by CCSM4 show a $0.05 \mathrm{~mm}$ increase in the ANN precipitation of the CA over the next 94 years under RCP4.5 and RCP8.5 scenarios. There will be no significant trends shown by WRFR2 experiment in this regard. The CCSM4 model projects that the DJF precipitation will increase by $0.12 \mathrm{~mm}$ under RCP4.5 scenario and $0.18 \mathrm{~mm}$ under the RCP8.5 scenario, whereas WRFR1 projects a $0.5 \mathrm{~mm}$ increase under RCP4.5 and a $0.8 \mathrm{~mm}$ increase under RCP8.5. The MAM, JJA, and SON precipitations projected by the CCSM4 model and WRFR1 experiment differ substantially. This is because the CA precipitation trends projected by CCSM4 and WRFR1 in these seasons are not significant, regardless of greenhouse gas emissions. The results from WRFR2 show different from WRFR1 in ANN precipitation with increasing significantly under RCP4.5 and decreasing significantly under RCP8.5

Figure 16 shows the spatial distribution of changes in the precipitation related indices. The projections by CCSM4 and dynamic downscaling differ to some extent. The CCSM4 model projects that $\mathrm{R} 10 \mathrm{~mm}$ will increase across the CA, with two significant high-value area in the northwestern $\mathrm{CA}$ and the Tibetan Plateau, and the projected results are similar under the RCP4.5 and RCP8.5 scenarios (Fig. 16a, e). The WRFR1 and WRFR2 also project that the R10mm of the CA will increase significantly, with high-value area in the northwestern China and the areas outside China's northwestern boundaries. The changes projected by WRFR1 and WRFR2 are also more significant than those from the CCSM4 model, with the former projecting that the maximum increase in R10mm will be more than 5 days (Fig. 16i, $\mathrm{m}, \mathrm{q}, \mathrm{u})$. However, the increase in ANN precipitation projected by the WRFR1 and WRFR2 is less significant than that of the CCSM4 model and hence, the increased precipitation projected by the WRFR 1 and WRFR 2 experiments mainly derives from increases in the number of days with more than $10 \mathrm{~mm}$ of precipitation. The changes of spatial distribution in PRCPTOT projected by the CCSM4 model are similar to the changes in R10mm. PRCPTOT is expected to increase significantly in the northwestern $\mathrm{CA}$ and the Tibetan Plateau. Furthermore, the increase projected by the CCSM4 model for PRCPTOT in the Tibetan Plateau is more significant under the RCP8.5 scenario than RCP4.5 scenario (Fig. 16b, f). The WRFR1 and WRFR2 experiments project that PRCPTOT will increase significantly in the CA, especially in the areas above the 50th parallel north and the Tibetan Plateau, by more than $100 \mathrm{~mm}$. These increases are significantly larger than those projected by the CCSM4 model (Fig. 16j, n, r, v). The CCSM4 model also projects that SDII will increase over the CA under the two greenhouse gas emission scenarios. The CCSM4-projected increase for SDII is larger in the lower latitudes than in the higher latitudes, with the maximum increase of $1.0 \mathrm{~mm} /$ day (Fig. 16c, g). The dynamic downscaling experiments show a more significant increase for SDII over the CA. Under the RCP4.5 and RCP8.5 scenarios, the WRFR1 and WRFR2 project that the increase of SDII in most parts of the CA will exceed $1.4 \mathrm{~mm} /$ day (Fig. 16k, o, s, w). The CCSM4 model projects that CDD will increase in Turkmenistan, Uzbekistan and the northeastern CA but decrease significantly in Xinjiang under both the RCP4.5 and RCP8.5 scenarios (Fig. 16d, h). The WRFR1 and WRFR2 projections show that CDD will decrease significantly in most parts of the CA under both greenhouse gas emission scenarios, especially in central CA and Xinjiang. The increase in ANN daily precipitation projected by the WRFR1 and WRFR2 experiments for 2007-2100 is less significant than that projected by the CCSM4 model (Fig. 16l, p, t, x).

In Fig. 17, it is shown that the WRFR2 experiment projects larger changes in R10mm, PRCPTOT and SDII than the CCSM4 model, but smaller changes in CDD. This is consistent with the preceding analysis regarding the changes in the climate indices that are projected by the CCSM4 and dynamic downscaling simulations. The differences between the WRFR2 and CCSM4 results are mainly caused by the tendency of the CCSM4 model to overestimate historical precipitation-related indices (Fig. 17a). The CCSM4 and WRFR1, WRFR2 project that R10mm will increase 0.7 days and 0.4 days, 0.6 days under the RCP4.5 scenario, and 1.1 days and 0.6 days, 0.7 days under the RCP8.5 scenario during 2006-2100. The CCSM4 model projects a larger increase in $\mathrm{R} 10 \mathrm{~mm}$ than the dynamic downscaling experiments. The CCSM4 model and WRFR1, WRFR2 experiment project that PRCPTOT will increase $19 \mathrm{~mm}$ and $6 \mathrm{~mm}, 18 \mathrm{~mm}$ under RCP4.5 during 2006-2100. Under RCP8.5, there will be less increase in WRFR2, and this is different from CCSM4 and WRFR1. The CCSM4 model and WRFR1, WRFR2 experiment project that the increase in SDII will be significantly larger under the RCP8.5 scenario than the RCP4.5 scenario. Therefore, the WRFR1 and WRFR2 experiments project a larger change for SDII than the CCSM4 model, and the projected SDII index will be affected by differences in greenhouse gas emissions. The CCSM4 model and WRFR1, WRFR2 experiment both show 
(a)

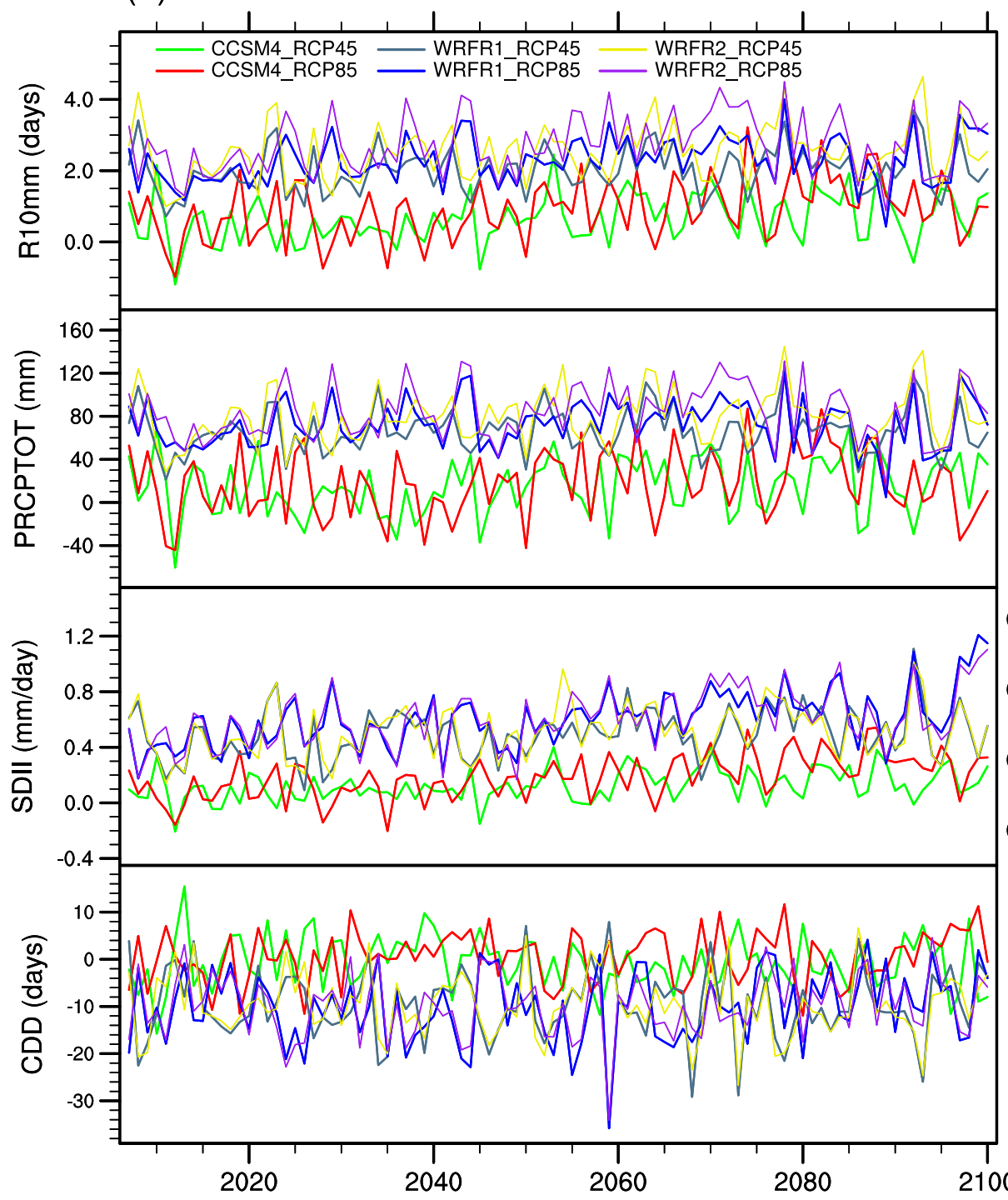

(b)

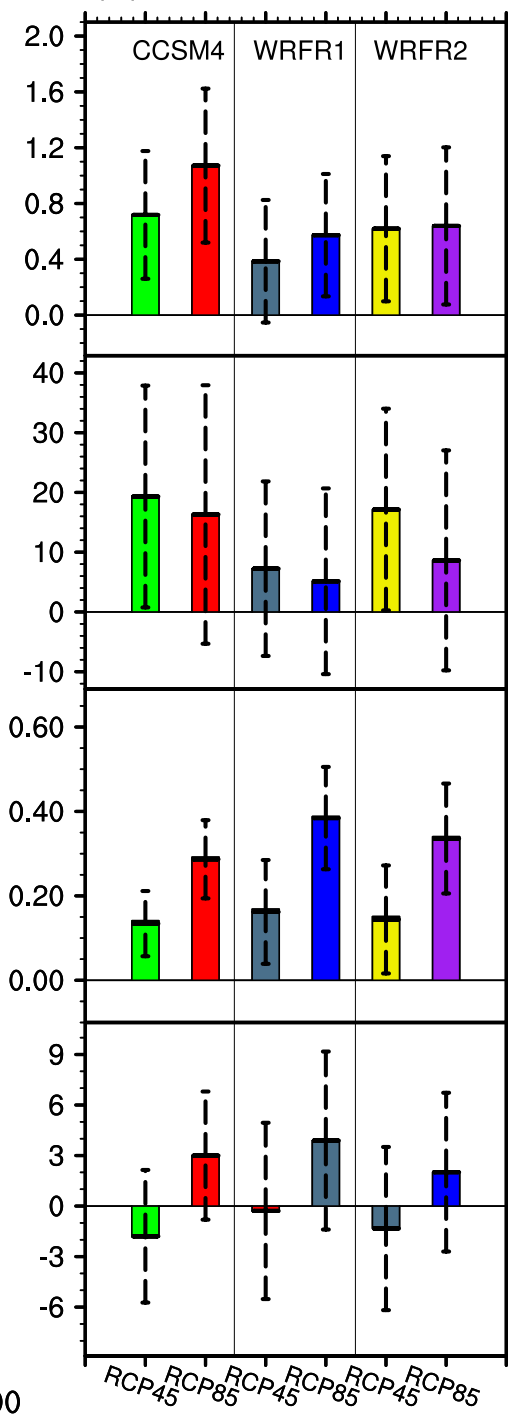

Fig. 17 Similar to Fig. 15, but for precipitation-related indices of R10mm, PRCPTOT, SDII, and CDD

that CDD will not change significantly under the two greenhouse gas emission scenarios. However, the CDD change is affected by greenhouse gas emissions (Fig. 17b).

In summary, the future precipitation changes of the CA are insignificant, and the precipitation of the CA is not significantly affected by the greenhouse gas emission scenario. Furthermore, the special features and temporal evolution of precipitation projected by the CCSM4 model and WRFR1, WRFR2 experiment for the CA differ more significantly than the projections of temperature. The CCSM4-projected increases in ANN and DJF precipitation are much more significant than those projected by the dynamic downscaling experiments. The projections from the CCSM4 model and dynamic downscaling experiments both show that the R10mm, PRCPTOT and SDII will increase significantly during the last few decades of the twenty-first century compared to the historical period. However, the CDD index did not change significantly, as shown by all the simulations, but the temporal trend of CDD will be impacted by greenhouse gas emissions. In the next few decades, the R10mm, PRCPTOT and SDII indices of the CA will rise, and the emission of GHG will affect the precipitation-related indices. As indicated above, there are some differences between the projections of the dynamic downscaling experiments and the CCSM4 model, but the consistent conclusion drawn is that there will be an impact on the precipitation-related extreme climate by greenhouse gas emissions in the future, particularly for CDD. 


\section{Discussion and conclusions}

In this paper, the WRFv3.7.1. model is used to conduct the dynamic downscaling for the ERA-Interim reanalysis dataset and the results of the CCSM4 model with two different land surface process parameterizations (Noah and Noah-MP). The impacts of different LSMs on the simulation of mean and extreme climate were then analyzed by comparing the results of the dynamic downscaling experiments, which is inadequate in the preceding researches about dynamical downscaling of climate change in CA (Ozturk et al. 2012; Mannig et al. 2013; Qiu et al. 2017). Dynamic downscaling and the CCSM4 model were then used to project the mean and extreme climate of the $\mathrm{CA}$ in future under two emission forcing scenarios. The main conclusions and considerations can be summarized as follows.

For the simulation of historical annual and seasonal mean temperature and precipitation over the CA, the results from dynamic downscaling show a significant improvement compared with the CCSM4 model. In particular, temperature improvement is more significant than that for precipitation. Obvious differences were shown between the dynamic downscaling experiments, with the results from WRFE2 and WRFC2 generally more similar to the observation than WRFE1 and WRFC1. Therefore, the Noah-MP is considered a more suitable LSM than Noah for the simulation of mean climate through dynamic downscaling by the WRF model.

The CCSM4 model and dynamic downscaling experiments were both able to reproduce the basic features of the extreme climate over the $\mathrm{CA}$, and the simulation for extreme temperature is better than for extreme precipitation. The results of the dynamic downscaling experiments were better than those of the CCSM4 model for the simulation of extreme climate, particularly for temperature-related indices. In contrast to the simulation of mean climate, there is insignificant impact by the LSM for the simulation of extreme climate through dynamic downscaling by WRF because the Noah-MP scheme is more suitable for the simulation of mean climate. Therefore, we only analyze the future mean and extreme climate over the CA simulated by CCSM4 and dynamic downscaling with the Noah-MP LSM.

The results of the CCSM4 model and dynamic downscaling experiments both show that the annual and seasonal temperatures over the CA will rise significantly in future, and the rise will mainly occur in the higher latitudes and highaltitude regions. The temperature will increase more significantly if there are more greenhouse gas emissions, especially for DJF. Under the RCP4.5 and RCP8.5 scenarios, the ANN temperature of the $\mathrm{CA}$ is projected to rise by $2.0^{\circ} \mathrm{C}$ and $5.0^{\circ} \mathrm{C}$ during the next few decades, respectively. Therefore, reinforcing greenhouse gas emission control is a priority for mitigating the warming. There will be more significant warming projected by the CCSM4 model than the dynamic downscaling experiment, which may be attributed to the tendency of the CCSM4 model to overestimate historical global temperature increase. Therefore, the dynamic downscaling may be able to reduce the model biases produced by the GCMs. There are no significant changes in the projected precipitation, and the impact of greenhouse gas emissions on the precipitation over the $\mathrm{CA}$ is also insignificant.

Similar to the mean temperature of the CA, the temperature-related indices (SU, TXX, and TNN) are projected to increase significantly in the future, and the number of low-temperature days (FD) will decrease. Furthermore, the increase in minimum temperature is projected to be significantly larger than the increase in maximum temperature. The change will be more significant under the RCP8.5 scenario than the RCP4.5 scenario.

The CCSM4 model projected larger increases in extreme temperature and decreases in the number of low temperature days than the dynamic downscaling experiment. The R10mm, PRCPTOT and SDII indices will increase significantly in the future, whereas the CDD index will not change significantly. These trends are generally more significant in the results of the dynamic downscaling experiment than those of the CCSM4 model. In contrast to the temperaturerelated indices, the change of precipitation-related indices will not be impacted much by greenhouse gas emissions. Some differences between the projections of the dynamic downscaling experiment and CCSM4 model were presented.

High resolution and quantity daily observation data for the $\mathrm{CA}$ is required model validation, which is a challenge in reality. The simulation by the RCM is significantly affected by the selection of LSMs and initial/boundary conditions. Therefore, the accuracy of the RCM simulations could be improved with the selection of an optimal LSM and driving fields. Aside from the LSM, the interactions between cumulus, radiation and cloud micro-physics parameterizations will also significantly influence the results of RCM simulations (Yang et al. 2015; Gao et al. 2016). Therefore, assessing the impact produced by parameterization during dynamic downscaling will be an important factor in our future work.

Vertical and horizontal resolutions are equally important for improving the accuracy of RCM simulations (Zhang et al. 2015); however, the impact on the simulation from the vertical resolution is complex. There is not a direct relation between increases in the vertical resolution and good performance of simulation. Therefore, the same vertical resolutions were used in the two domains in this study. Unfortunately, the comparison for the impact from different vertical resolutions in the dynamic downscaling was not conducted in this work and there is also a practical 
need to analyze the importance of vertical resolution in the future.

With computer resource limitations, only one GCM output was used for the dynamic downscaling simulation. There are significant uncertainties in the dynamic downscaling simulation, so the credibility of projections for future climate change is not very high, particularly at regional and local scales. An important and effective way to reduce these uncertainties is downscaling multi-models and their ensembles. Multiple GCMs will be selected to conduct dynamic downscaling, and run more dynamical simulations to reduce the uncertainty of future climate projection. The model domain will be further expanded to submit the simulation dataset to the CORDEX project.

Acknowledgements This work was funded by National Key R\&D Program of China (2016YFA0602703), the National Natural Science Foundation of China (91644225), the Strategic Priority Research Program of Chinese Academy of Sciences (XDA20060401). Project supported by State Key Laboratory of Earth Surface Processes and Resource Ecology (2017-FX-03(3)) and Youth Innovative Talents Project in Guangdong Colleges and Universities (201712011QX). Special thanks to NCAR for releasing the data of the CESM Global Bias-Corrected CMIP5 Output to Support WRF/MPAS Research. The CCSM4 model outputs were acquired from the Web site at https://esgf-node. llnl.gov/search/cmip5/. The ERA-Interim reanalysis data were acquired from the website of the European Centre for Medium Range Weather Forecasts: https://www.ecmwf.int/en/forecasts/datasets/reanalysis-datas ets. The CPC Global Temperature and Precipitation data provided by the NOAA/OAR/ESRL PSD, Boulder, Colorado, USA, were acquired from their Web site at https://www.esrl.noaa.gov/psd/. The authors are grateful to NCAR, Boulder, Colorado, USA for making the WRF-ARW model available. We thank the editor and reviewers for their valuable comments leading to improvements of this manuscript.

Open Access This article is licensed under a Creative Commons Attribution 4.0 International License, which permits use, sharing, adaptation, distribution and reproduction in any medium or format, as long as you give appropriate credit to the original author(s) and the source, provide a link to the Creative Commons licence, and indicate if changes were made. The images or other third party material in this article are included in the article's Creative Commons licence, unless indicated otherwise in a credit line to the material. If material is not included in the article's Creative Commons licence and your intended use is not permitted by statutory regulation or exceeds the permitted use, you will need to obtain permission directly from the copyright holder. To view a copy of this licence, visit http://creativecommons.org/licenses/by/4.0/.

\section{References}

Bruyère CL, Done JM, Holland GJ, Fredrick S (2014) Bias corrections of global models for regional climate simulations of high-impact weather. Clim Dyn 43:1847-1856

Chen M, Xie P, Janowiak JE, Arkin PA (2002) Global land precipitation: a 50-yr monthly analysis based on gauge observations. J Hydrometeorol 3:249-266

Chen F, Wang J, Jin L, Zhang Q, Li J, Chen J (2009) Rapid warming in mid-latitude central Asia for the past 100 years. Front Earth Sci China 3:42-50
Chen F, Huang W, Jin L, Chen J, Wang J (2011) Spatiotemporal precipitation variations in the arid Central Asia in the context of global warming. Sci China Earth Sci 4:1812-1821

Chen FM, Barlage M, Tewari R, Rasmussen R, Jin J, Lettenmaier D, Livneh B, Lin C, Miguez-Macho G, Niu G-Y, Wen L, Yang Z-L (2014) Modeling seasonal snowpack evolution in the complex terrain and forested Colorado Headwaters region: a model intercomparison study. J Geophys Res 119:13795-13819. https://doi. org/10.1002/2014JD022167

Collins WD et al (2004) Description of the NCAR community atmosphere model (CAM 3.0). NCAR technical note NCAR/TN464+STR. https://doi.org/10.5065/D63N21CH

Davi NK, D'Arrigo RD, Jacoby GC, Cook ER, Anchukaitis KJ, Nachin B, Rao MP, Leland C (2015) A long-term context (931-2005 C.E.) for rapid warming over Central Asia. Q Sci Rev 121:89-97

Fan Y, Van den Dool HA (2008) Global monthly land surface air temperature analysis for 1948-present. J Geophys Res Atmos 113:D01103

Frich P, Alexander LV, Della-Marta P, Gleason B, Haylock M, Klein Tank AMG, Peterson T (2002) Observed coherent changes in climatic extremes during the second half of the twentieth century. Clim Res 19:193-212

Gao XJ, Xu Y, Zhao ZC, Pal JS, Giorgi F (2006) On the role of resolution and topography in the simulation of east Asia precipitation. Theor Appl Climatol 86(1-4):173-185. https://doi.org/10.1007/ s00704-005-0214-4

Gao Y, Cuo L, Zhang Y (2014) Changes in moisture flux over the Tibetan Plateau during 1979-2011 and possible mechanisms. J Clim 27:1876-1893. https://doi.org/10.1175/JCLI-D-13-00321.1

Gao XJ, Shi Y, Giorgi F (2016) Comparison of convective parameterizations in RegCM4 experiments with CLM as the land surface model over China. Atmos Ocean Sci Lett 9(4):246-254

Gao Y, Xiao L, Chen D et al (2017) Quantification of the relative role of land-surface processes and large-scale forcing in dynamic downscaling over the Tibetan Plateau. Clim Dyn 48:1705-1721

Giorgi F (2006) Climate change hot-spots. Geophys Res Lett 33:L08707. https://doi.org/10.1029/2006GL025734

Giorgi F (2019) Thirty years of regional climate modeling: where are we and where are we going next? J Geophys Res Atmos. https:// doi.org/10.1029/2018JD030094

Grell GA, Freitas SR (2014) A scale and aerosol aware stochastic convective parameterization for weather and air quality modeling. Atmos Chem Phys 14:5233-5250. https://doi.org/10.5194/ acp-14-5233-2014

Hong S-Y, Lim J-OJ (2006) The WRF single-moment 6-class microphysics scheme (WSM6). J Korean Meteorol Soc 42:129-151

Hong S-Y, Kanamitsu M (2014) Dynamical downscaling: fundamental issues from an NWP point of view and recommendations. Asia Pac J Atmos Sci 50(1):83-104

Hong SY, Dudhia J, Chen SH (2004) A revised approach to ice microphysical processes for the bulk parameterization of clouds and precipitation. Mon Weather Rev 132:103-120

Hu Z, Zhang C, Hu Q, Tian H (2014) Temperature changes in central Asia from 1979 to 2011 based on multiple datasets. J Clim 27:1143-1167

Hu Z, Zhou Q, Chen X et al (2017) Variations and changes of annual precipitation in Central Asia over the last century. Int J Climatol 37(S1):157-170. https://doi.org/10.1002/joc.4988

Huang AN, Zhou Y, Zhang YC, Huang DQ, Zhao Y, Wu HW (2014) Changes of the annual precipitation over central Asia in the twenty-first century projected by multi-models of CMIP5. J Clim 27:6627-6646

IPCC (2013) Climate change 2013: the physical science basis. In: Contribution of working group I to the fifth assessment report of the intergovernmental panel on climate change. Cambridge University Press, Cambridge 
Ji Z, Kang S (2013) Double nested dynamical downscaling experiments over the Tibetan Plateau and their projection of climate change under RCPs scenarios. J Atmos Sci 70:1278-1290

Ji Z, Kang S (2015) Evaluation of extreme climate events using a regional climate model for China. Int J Climatol 35:888-902

Kala J, Andrys J, Lyons TJ, Foster IJ, Evans BJ (2015) Sensitivity of WRF to driving data and physics options on a seasonal time-scale for the southwest of Western Australia. Clim Dyn 44:633-659

Karl TR, Nicholls N, Ghazi A (1999) CLIVAR/GCOS/WMO workshop on indices and indicators for climate extremes: workshop summary. Clim Change 42:3-7

Leung LR, Kuo YH, Tribbia J (2006) Research needs and directions of regional climate modeling using WRF and CCSM. Bull Am Meteorol Soc 87:1747-1751

Li C, Zhang C, Luo G, Chen X, Maisupova B, Madaminov AA, Han Q, Djenbaev BM (2015) Carbon stock and its responses to climate change in Central Asia. Glob Change Biol 21:1951-1967

Mannig B, Muller M, Starke E, Merkenschlager C, Mao W, Zhi X, Podzun R, Jacob D, Paeth H (2013) Dynamical downscaling of climate change in Central Asia. Glob Planet Change 110:26-39

Meehl GA, Covey C, Taylor KE, Delworth T, Stouffer RJ, Latif M, McAvaney B, Mitchell JF (2007) The WCRP CMIP3 multimodel dataset: a new era in climate change research. Bull Am Meteorol Soc 88:1383-1394

Narama C, Kääb A, Duishonakunov M, Abdrakhmatov K (2009) Spatial variability of recent glacier area changes in the Tien Shan Mountains, central Asia, using Corona ( 970), Landsat ( 2000), and ALOS ( 2007) satellite data. Glob Planet Change 71:42-54

Narisma GT, Foley JA, Licker R, Ramankutty N (2007) Abrupt changes in rainfall during the twentieth century. Geophys Res Lett 34:L06710. https://doi.org/10.1029/2006GL028628

Niu GY et al (2011) The community Noah land surface model with multiparameterization options (Noah-MP): 1. Model description and evaluation with local-scale measurements. J Geophys Res 116:D12109

Niu XR, Wang SY, Tang JP, Lee D-K, Gao XJ, Wu J, Hong SY et al (2015) Multimodel ensemble projection of precipitation in eastern China under A1B emission scenario. J Geophys Res Atmos 120(19):9965-9980. https://doi.org/10.1002/2015JD023853

Ozturk T, Altinsoy H, Türkeş M, Kurnaz ML (2012) Simulation of temperature and precipitation climatology for the central Asia cordex domain using REEGCM 4.0. Clim Res 52:63-76

Pan S, Tian H, Dangal SR, Zhang C, Yang J, Tao B, Ouyang Z, Wang X, Lu C, Ren W (2014) Complex spatiotemporal responses of global terrestrial primary production to climate change and increasing atmospheric $\mathrm{CO}_{2}$ in the 21 st century. PLoS One 9:e112810

Peng D, Zhou T, Zhang LZ, Zou L (2019) Detecting human influence on the temperature changes in central Asia. Clim Dyn 53(7-8):4553-4568

Qiu Y, Hu Q, Zhang C (2017) WRF simulation and downscaling of local climate in central Asia. Int J Climatol 37:513-528

Rasmussen R, Liu C, Ikeda K et al (2011) High-resolution coupled climate runoff simulations of seasonal snowfall over Colorado: a process study of current and warmer climate. J Clim 24:30153048. https://doi.org/10.1175/2010JCLI3985.1

Shi Y, Wang GL, Gao XJ (2017) Role of resolution in regional climate change projections over China. Clim Dyn 51:2375-2396. https:// doi.org/10.1007/s00382-017-4018-x

Skamarock WC, Klemp JB, Dudhia J, Gill DO, Barker DM, Wang W, Powers JG (2005) A description of the Advanced research WRF version 2. NCAR Tech. Note NCAR/TN-468STR, 88 pp

Taylor KE, Stouffer RJ, Meehl GA (2012) An overview of CMIP5 and the experiment design. Bull Am Meteorol Soc 93:485-498. https ://doi.org/10.1175/bams-d-11-00094.1
Tewari M, Chen F, Wang W (2004) Implementation and verification of the unified NOAH land surface model in the WRF model. In: Proceedings of the 20th conference on weather analysis and forecasting/16th conference on numerical weather prediction. American Meteorological Society, Seattle, WA, US, pp 11-15

Viviroli D et al (2011) Climate change and mountain water resources: overview and recommendations for research, management and policy. Hydrol Earth Syst Sci 15:471-504

Wang AH, Zeng XB (2012) Evaluation of multireanalysis products with in situ observations over the Tibetan Plateau. J Geophys Res Atmos. https://doi.org/10.1029/2011jd016553

Wang YJ, Zhou BT, Qin DH, Wu J, Gao R, Song LC (2017) Changes in mean and extreme temperature and precipitation over the arid region of northwestern China: observation and projection. Adv Atmos Sci 34(3):287-305. https://doi.org/10.1007/s0037 6-016-6160-5

Wei ZG, Dong WJ (2015) Assessment of simulations of snow depth in the Qinghai-Tibetan plateau using CMIP5 multi-models. Arct Antarct Alp Res 47:611-625

Wu J, Gao XJ (2013) A gridded daily observation dataset over china region and comparison with the other datasets. Chin J Geophys 56:1102-1111. https://doi.org/10.6038/cjg20130406

Wu X, Guo W, Liu H, Li X, Peng C, Allen CD, Zhang C, Wang P, Pei T, Ma Y, Tian Y, Song Z, Zhu W, Wang Y, Li Z, Chen D (2019) Exposures to extremely high temperature reduce vegetation activity in the northern hemisphere. Natl Sci Rev. https://doi. org/10.1093/nsr/nwy 158

Xu Z, Yang Z-L (2015) A new dynamical downscaling approach with GCM bias corrections and spectral nudging. J Geophys Res Atmos 120:3063-3084

Xu J, Gao Y, Chen D, Xiao L, Ou T (2017) Evaluation of global climate models for downscaling applications centered over the Tibetan plateau. Int J Climatol 37:657-671

Xue Y, Janjic Z, Dudhia J, Vasic R, De Sales F (2014) A review on regional dynamical downscaling in intraseasonal to seasonal simulation/prediction and major factors that affect downscaling ability. Atmos Res 147-148:68-85

Yang ZL, Niu GY, Mitchell K et al (2011) The community Noah land surface model with multiple parameterization options (NoahMP): 2. Evaluation over global river basins. J Geophys Res 116:D12110. https://doi.org/10.1029/2010jd015140

Yang B, Zhang YC, Qian Y, Huang AM, Yan HP (2015) Calibration of a convective parameterization scheme in the WRF model and its impact on the simulation of East Asian summer monsoon precipitation. Clim Dyn 44:1661-1684

You Q, Min J, Kang S (2016) Rapid warming in the Tibetan Plateau from observations and CMIP5 models in recent decades. Int $\mathrm{J}$ Climatol 36:2660-2670

You Q, Jiang Z, Wang D, Pepin N, Kang S (2018) Simulation of temperature extremes in the Tibetan plateau from CMIP5 models and comparison with gridded observations. Clim Dyn 51:355-369

Zhang C, Ren W (2017) Complex climatic and $\mathrm{CO}_{2}$ controls on net primary productivity of temperate dryland ecosystems over Central Asia during 1980-2014. J Geophys Res Biogeo 122:2356-2374

Zhang XB, Alexander L, Hegerl GC, Jones P, Tank A, Peterson TC, Trewin B, Zwiers FW (2011) Indices for monitoring changes in extremes based on daily temperature and precipitation data. WIREs Clim Change 2:851-870

Zhang DL, Zhu L, Zhang XJ et al (2015) Sensitivity of idealized hurricane intensity and structures under varying background flows and initial vortex intensities to different vertical resolutions in HWRF. Mon Weather Rev 143(3):914-932

Zhang C, Lu D, Chen X, Zhang Y, Maisupova B, Tao Y (2016) The spatiotemporal patterns of vegetation coverage and biomass of the temperate deserts in central Asia and their relationships with climate controls. Remote Sens Environ 175:271-281 
Zhu X, Dong W, Wei Z, Guo Y, Gao X, Wen X, Yang S, Zheng Z, Yan D, Zhu Y, Chen J (2017) Multi-decadal evolution characteristics of global surface temperature anomaly data shown by observation and CMIP5 models. Int J Climatol 38:1533-1542

Zhu X, Wei Z, Dong W et al (2019) Projected temperature and precipitation changes on the Tibetan plateau: results from dynamical downscaling and CCSM4. Theor Appl Climatol 138(1-2):861-875
Publisher's Note Springer Nature remains neutral with regard to jurisdictional claims in published maps and institutional affiliations. 